Yumi Hasegawa Maekawa

\title{
Detecção e caracterização de células epiteliais no sangue periférico de pacientes com carcinoma localmente avançado de mama
}

Dissertação apresentada à Faculdade de Medicina da Universidade de São Paulo para obtenção do título de Mestre em Ciências

Área de concentração: Obstetrícia e Ginecologia Orientador: Prof. Dr. José Aristodemo Pinotti

São Paulo 2007 
Yumi Hasegawa Maekawa

\title{
Detecção e caracterização de células epiteliais no sangue periférico de pacientes com carcinoma localmente avançado de mama
}

\author{
Dissertação apresentada à Faculdade de \\ Medicina da Universidade de São Paulo para \\ obtenção do título de Mestre em Ciências \\ Área de concentração: Obstetrícia e Ginecologia \\ Orientador: Prof. Dr. José Aristodemo Pinotti
}

São Paulo

2007 
Dedico este projeto

Ao meu marido Ryuiti Maekawa, que de forma paciente, compreendeu minha ausência, oferecendo apoio constante;

Ao meu querido filho César Kenzo Maekawa, o qual a pureza e a ingenuidade da infância me fazem refletir sobre os verdadeiros valores da vida.

Aos meus pais pelo amor, esforços e dedicação à minha formação pessoal e profissional. 


\section{AGRADEÇO}

Ao Prof. Dr. José Aristodemo Pinotti, pelo exemplo acadêmico e pela oportunidade concedida para a realização deste projeto.

À Prof ${ }^{a}$. Dr ${ }^{\text {a }}$. Angela Maggio da Fonseca, coordenadora do Programa de Pós Graduação do Departamento de Obstetrícia e Ginecologia da Faculdade de Medicina da Universidade de São Paulo, pelo incansável apoio e colaboração.

Ao Prof. Dr. Edmund Chada Baracat, pela orientação, apoio e amizade nos momentos mais difíceis.

Ao Dr. Antônio Carlos Toshihiro Nisida pela colaboração na coleta dos materiais.

Ao Dr. Oscar de Almeida Junior, médico do Centro de Referência da Saúde da Mulher (CRSM), pela paciência e valiosa contribuição.

À Drª . Mariane Pinotti, pela contribuição na execução do projeto.

À Neusa secretária da oncologia clínica pelo apoio e coleta de dados das pacientes. 
Às enfermeiras do CRSM, em especial: Elisangela Corrêa Rizo, Maria Almerinda Silva e Simone Vieira Rebelo do setor de mamotomia que me ajudaram a selecionar e colher as amostras das pacientes;

À Denise, Simone, Angela, Madalena, Jussara e todas as enfermeiras do setor de quimioterapia que coletavam as amostras antes da medicação;

À Maria José (Zezé da coleta) que pacientemente me auxiliava nas coletas das pacientes internadas;

À Raquel Ribeiro Bezerra do centro cirúrgico que armazenava as amostras, colhidas durante as cirurgias.

Às enfermeiras do Hospital das Clínicas (HC).

À secretária Cláudia Vieira, pela atenção, paciência e disponibilidade.

À minha colega de trabalho, Nair Tamashiro, pela paciência e compreensão.

Às minhas auxiliares Maria Helena Borges e Maria de Fátima da Cruz Souza que zelam pela organização de minha casa. 
A todas as mulheres que, em momentos tão difíceis de suas vidas, tornaram possível a realização deste estudo. 


\section{Normatização Adotada}

Esta tese está de acordo com as seguintes normas em vigor no momento desta publicação:

- Referências: adaptado de International Commitee of Medical Journal Editors (Vancouver).

- Universidade de São Paulo. Faculdade de Medicina. Serviço de biblioteca e documentação. Guia de apresentação de dissertações, teses e monografias.

- Elaborado por Anneliese Carneiro da Cunha, Maria Julia de A. L. Freddi, Maria F. Crestana, Marinalva de Souza Aragão, Suely Campos Cardoso, Valéria Vilhena. $2^{\underline{a}}$ ed. São Paulo: Serviço de biblioteca e documentação; 2-5.

- Abreviaturas dos títulos dos periódicos de acordo com List of Journals Indexed in Index Medicus. 


\section{SUMÁRIO}

Lista de Abreviaturas

Resumo

Summary

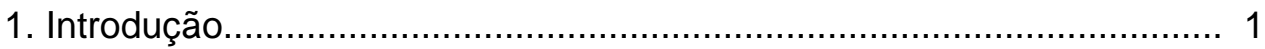

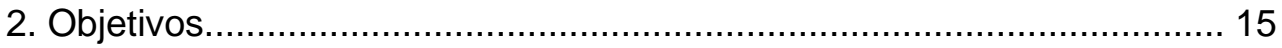

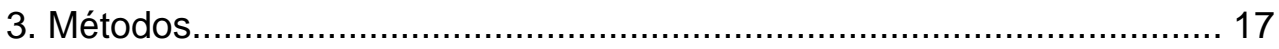

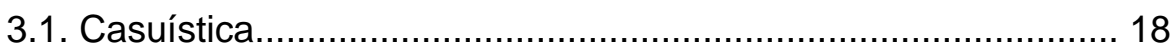

Critérios de inclusão............................................................ 19

Critérios de exclusão............................................................. 19

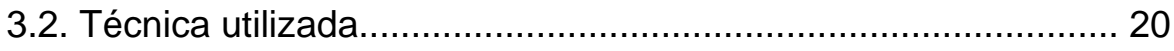

3.2.1. Material do sangue periférico.................................... 21

3.2.2. Material de fragmento de tumor................................. 21

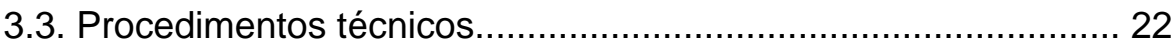

3.3.1. Fases para obtenção das células epiteliais................... 22

Fase $1 \quad$ a) Preparo da amostra..................................... 22

b) Separação imunomagnética......................... 23

Fase $2 \quad$ a) Reação imunocitoquímica............................. 25

b) Reação primária........................................... 25

c) Reação secundária...................................... 26

d) Revelação e coloração................................. 26

e) Desidratação............................................... 27

f) Montagem das lâminas................................ 27 
g) Leitura..................................................... 27

h) Interpretação............................................ 28

3.3.2. Quantificação do DNA celular no carcinoma de mama........... 29

3.3.3. Análise por citometria de fluxo............................................... 33

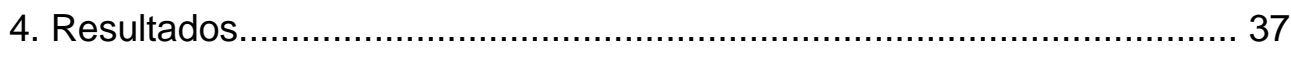

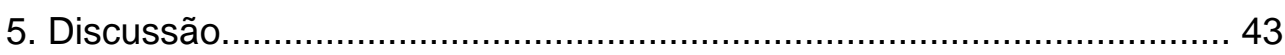

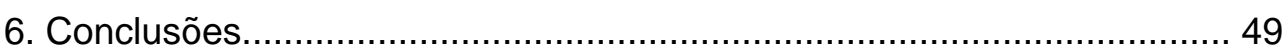

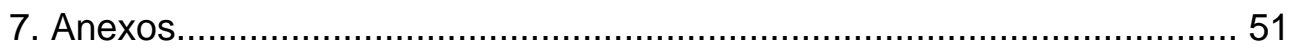

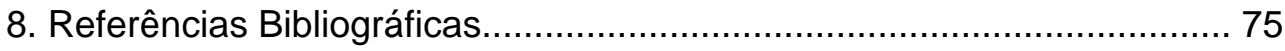




\section{LISTA DE ANEXOS}

Anexo A - Aprovação do projeto................................................................... 52

Anexo B-Termo de consentimento informado CRSM .................................. 53

Anexo C-Termo de consentimento informado Hospital das clínicas............ 56

Anexo D - Dados relevantes das pacientes do Grupo A............................ 59

Anexo E-Dados relevantes das pacientes do Grupo B.............................. 61

Anexo F-Hemograma do Grupo A ......................................................... 62

Anexo G-Hemograma do Grupo B....................................................... 63

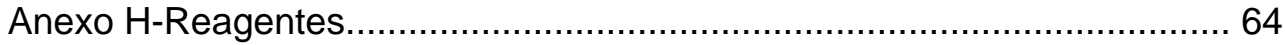

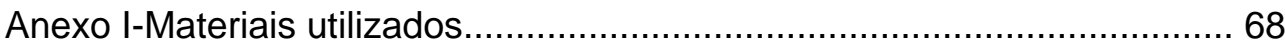

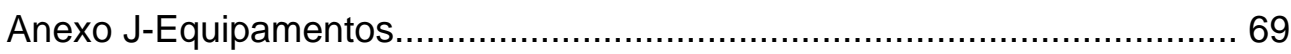

Anexo K-Preparo das lâminas de silane...................................................... 70

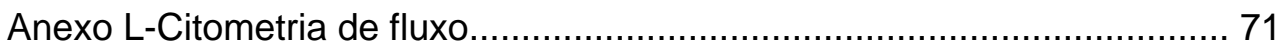




\section{LISTA DE ABREVIATURAS}

$\begin{array}{ll}\text { APAAP } & \text { fosfatase alcalina anti-fosfatase alcalina } \\ \text { BD } & \text { Becton Dickinson } \\ \text { Ca } & \text { carcinoma } \\ \text { CEA } & \text { antígeno carcinoembriônico } \\ \text { CK } & \text { citoqueratina } \\ \text { CMF } & \text { citometria de fluxo } \\ \text { DAB } & \text { diamino benzidina } \\ \text { EDTA } & \text { etilenodiamino tetracético } \\ \text { Et al } & \text { e outros } \\ \text { Hb } & \text { hemoglobina } \\ \text { ICC } & \text { imunocitoquímica } \\ \text { IDNA } & \text { índice de DNA } \\ \text { IMS } & \text { separação imunomagnética } \\ \text { Linfo } & \text { linfócitos } \\ \text { Neutro } & \text { neutrófilos } \\ \text { Nr } & \text { não realizado } \\ \text { Plaq } & \text { plaquetas } \\ \text { PCR } & \text { reação em cadeia da polimerase } \\ \text { RPMI } & \text { Roswell Park Memorial Institute } \\ \text { RT-PCR } & \text { reação em cadeia da polimerase em tempo real } \\ \text { SBF } & \text { soro bovino fetal } \\ \text { UICC } & \text { União Internacional Contra o Câncer } \\ \text { volume corpuscular médio }\end{array}$




\section{Resumo}

O projeto tem como objetivo a detecção e caracterização das células epiteliais circulantes de pacientes com carcinoma de mama no estádio III. Analisou-se a presença ou ausência destas células antes da realização de

quimioterapia neoadjuvante. Para tanto, utilizou-se o sistema de enriquecimento de amostras de sangue periférico por meio da marcação intracelular imunomagnética direta, empregando-se "microbeads" conjugados com citoqueratina e posterior separação imunomagnética. A amostra final, com as células alvo detectadas, foi então quantificada por imunocitoquímica ou citometria de fluxo. Resultados: A reação de imunocitoquímica no sangue periférico foi negativa em todos os casos enquanto que na citometria de fluxo foi positiva em $22 / 23$ casos analisados. Conclusão: A detecção e caracterização de células tumorais circulantes em pacientes com câncer de mama podem vir a se constituir em um novo fator prognóstico, porém, são ainda necessárias novas estratégias para melhor detectá-las. 


\section{Summary}

The aim of this study was to detect and characterize carcinoma cells of patients with breast cancer with clinical stage III analyzing the presence or absence before chemotherapy by enrichment of peripheral blood with super paramagnetic microbeads, using direct Immunomagnetic labeling of intracellular $7 / 8$ cytokeratin. For enrichment, magnetically labeled tumor cells are passed over a high-gradient magnetic positive selection column.

Cytospin preparations are made after immunomagnetic enrichment and are examined immunocytochemically (ICC) using an anti-cytokeratin and quantified by flow cytometry (CMF). Results: No cytokeratin positive cells were detected in the 32 peripheral blood of patients of breast carcinoma by ICC and cytokeratin positive cells were detected in the 22 of 23 patients by CMF. Conclusion: These methods of detection and characterization breast carcinoma cells will become useful in the diagnosis and prognosis but is necessary optimization of existing methods. 
INTRODUÇÃO 


\section{INTRODUÇÃO}

Nas últimas décadas, significativo aumento da incidência do câncer de mama tem ocorrido em todo o mundo (Johnson-Thompson \& Guthrie, 2000).

O câncer de mama ainda é a neoplasia mais freqüente em países desenvolvidos, afetando 1 de cada 6 a 7 mulheres até a idade de 70 anos (Chabannon et al, 2001).

Apesar da aparente cura após a cirurgia, mais de $50 \%$ das mulheres com câncer de mama têm recidiva dentro de 5 anos após o diagnóstico. Nestas pacientes, é a metástase e não o tumor primário a principal causa de morte (Bischoff et al, 2003; Weigelt et al, 2005, Braun et al, 2000). Há elevada probabilidade de que já exista metástase quando o câncer de mama é diagnosticado ainda em estádio precoce (Lalle et al, 2000; Gaforio et al, 2003).

Atualmente o surgimento de metástase e a mortalidade em decorrência do câncer de mama têm diminuído devido ao diagnóstico precoce, rastreamento mamográfico e implementação da quimioterapia adjuvante (Weigelt et al, 2005). A indicação da quimioterapia neoadjuvante é determinada por inúmeros fatores, sendo a presença ou ausência de metástase no linfonodo axilar, o fator preditivo mais importante (KasimirBauer et al, 2002).

Entre as vantagens da quimioterapia neoadjuvante, realça a possibilidade de redução da massa tumoral proporcionando diminuição da extensão da cirurgia, tornando o tumor antes irressecável em ressecável, 
além de atuar na doença metastática microscópica (Hortobagyi, 1994; Fisher \& Mamounas, 1995).

A quimioterapia neoadjuvante auxilia na erradicação das células tumorais que podem ter se espalhado para locais distantes do tumor primário. Em mulheres com câncer de mama com menos de 50 anos, a quimioterapia neoadjuvante aumentou a sobrevida em 10\% em 15 anos e, em mulheres com mais de 50 anos, em 3\% em 15 anos. Não é possível predizer o risco de se desenvolver metástase; atualmente mais de $80 \%$ delas recebem quimioterapia adjuvante, embora aproximadamente $40 \%$ das pacientes recaem e morrem por metástase de câncer de mama (Wegelt et al, 2005).

A quimioterapia neoadjuvante pode ser aplicada em pacientes com boas condições clínicas gerais e, portanto, aptas a suportar os seus efeitos colaterais, uma vez que o aporte sangüíneo para o tumor não foi alterado pela radioterapia e/ou pela cirurgia. A condição básica para esta terapia é que o tumor seja mensurável (Hortobagyi, 1994; Fisher \& Mamounas, 1995).

O câncer de mama é, clinicamente, uma doença heterogênea; aproximadamente $10 \%$ a $15 \%$ das pacientes têm doença agressiva e desenvolvem metástase à distância dentro de 3 anos após a detecção inicial do tumor primário. Entretanto, a manifestação clínica da metástase à distância em 10 anos ou mais após o diagnóstico não é usual. A heterogeneidade da doença dificulta a cura, assim como também o estabelecimento dos fatores de risco para metástase (Weigelt et al, 2005). 
Ao que tudo indica, o câncer de mama é o resultado da interação de fatores genéticos, estilo de vida, hábitos reprodutivos e meio ambiente (Johnson-Thompson \& Guthrie, 2000).

Provavelmente o câncer de mama tem origem genética. Cerca de 90\% a 95\% são considerados esporádicos (não-familiares) e decorrem de mutações somáticas que se verificam durante a vida. Em torno de 5\% a 10\% seriam, por sua vez, hereditários (familiares), devido à herança de uma mutação germinativa ao nascimento, que confere a estas mulheres suscetibilidade ao câncer de mama (Bilmoria \& Morrow, 1995).

É considerado uma doença sistêmica porque a disseminação das células tumorais podem ocorrer em tumores ainda pequenos (Pierga et al, 2004), logo após tornar-se invasivo, migrando para as vias linfáticas (Taubert et al, 2004).

As células do câncer de mama, uma vez disseminadas, podem formar metástases em vários órgãos. Os locais mais comuns são os ossos, pulmões e fígado; com freqüência desenvolvem-se metástases em múltiplos sítios (Fetsch et al, 2000; Weigelt et al, 2005).

Após o diagnóstico de carcinoma de mama, vários fatores clinicopatológicos, como tamanho do tumor, metástase linfonodal axilar, metástase sistêmica, histologia do tumor e receptor hormonal, têm determinado o prognóstico e o tratamento neoadjuvante (Pierga et al, 2004; Janni et al, 2000; Kasimir-Bauer, 2002).

O receptor de estrogênio é um dos fatores preditivos importantes para determinar o tratamento e o prognóstico (Gaforio et al, 2003). A sua 
presença se correlaciona com prognóstico favorável, além de ser um fator preditivo da resposta ao tratamento hormonal.

Gaforio et al (2003) investigaram o sangue periférico (volume $10 \mathrm{~mL}$ ) de 92 pacientes com carcinoma de mama antes do início da quimioterapia, sendo 25 neoadjuvantes, 42 adjuvantes e 25 metastáticos. Observaram que houve diferença significante na presença de células citoqueratinas positivas de acordo com a expressão do receptor de estrogênio $(p=0,049)$ e o estado linfonodal $(p=0,033)$, mas não houve diferença para idade, estado menopausal, tipo de tratamento (neoadjuvante, adjuvante, metastático), classificação TNM, tipo histológico, expressão do receptor de progesterona, expressão de C-erb B2, p53 e Ki-67. Concluíram que a detecção de células citoqueratinas positivas antes do início da quimioterapia poderia identificar as pacientes de mau prognóstico.

Tumores sem receptor para estrogênio apresentam alta taxa de proliferação celular, o que faz supor maior resposta à quimioterapia (Lippman et al, 1978).

O sistema de estadiamento de tumores malignos mais utilizado é o preconizado pela União Internacional Contra o Câncer (UICC), denominado Sistema TNM. Esta classificação baseia-se na extensão anatômica da doença, levando em conta as características do tumor primário (T) e dos linfonodos das cadeias de drenagem linfática do órgão onde está localizado o tumor (ou do sítio do tumor) (N) e a presença ou ausência de metástases à distância (M) (Quadro 1). 
Quadro 1-Classificação TNM para o câncer de mama

Grupamento por estádios

UICC - União Internacional Contra o Câncer - TNM 6ª edição, 2002.

\begin{tabular}{|l|l|l|l|}
\hline Estádio 0 & Tis & N0 & M0 \\
\hline Estádio I & $\mathrm{T}^{*}$ & $\mathrm{~N} 0$ & $\mathrm{M} 0$ \\
\hline \multirow{5}{*}{ Estádio IIA } & $\mathrm{T} 0$ & $\mathrm{~N} 1$ & $\mathrm{M} 0$ \\
\cline { 2 - 4 } & $\mathrm{T} 1^{*}$ & $\mathrm{~N} 1$ & $\mathrm{M} 0$ \\
\cline { 2 - 4 } & $\mathrm{T} 2$ & $\mathrm{~N} 0$ & $\mathrm{M} 0$ \\
\hline \multirow{2}{*}{ Estádio IIB } & $\mathrm{T} 2$ & $\mathrm{~N} 1$ & $\mathrm{M} 0$ \\
\cline { 2 - 4 } & $\mathrm{T} 3$ & $\mathrm{~N} 0$ & $\mathrm{M} 0$ \\
\hline \multirow{5}{*}{ Estádio IIIA } & $\mathrm{T} 0$ & $\mathrm{~N} 2$ & $\mathrm{M} 0$ \\
\cline { 2 - 4 } & $\mathrm{T} 1^{*}$ & $\mathrm{~N} 2$ & $\mathrm{M} 0$ \\
\cline { 2 - 4 } & $\mathrm{T} 2$ & $\mathrm{~N} 2$ & $\mathrm{M} 0$ \\
\cline { 2 - 4 } & $\mathrm{T} 3$ & $\mathrm{~N} 1, \mathrm{~N} 2$ & $\mathrm{M} 0$ \\
\hline Estádio IIIB & $\mathrm{T} 4$ & $\mathrm{~N} 0, \mathrm{~N} 1, \mathrm{~N} 2$ & $\mathrm{M} 0$ \\
\hline Estádio IIIC & Qualquer T & $\mathrm{N} 3$ & $\mathrm{M} 0$ \\
\hline Estádio IV & Qualquer T & Qualquer N & $\mathrm{M} 1$ \\
\hline
\end{tabular}

O estadiamento clínico baseia-se nos achados clínicos, radiológicos e o estádio patológico da peça operatória; determina a extensão da doença com maior precisão.

O estádio do câncer de mama varia de 0 a IV, crescentes de acordo com a gravidade da doença. A graduação histológica representa uma medida da diferenciação celular. Ela se aplica principalmente nos carcinomas ductais invasivos e foi escrita originalmente por Bloom e Richardson, em 1957 (citado por Pinotti, 2003), que a expressaram em 3 graus: I ou bem diferenciado, II ou moderadamente diferenciado e III ou pouco diferenciado.

O grau nuclear é baseado na descrição de Black e Speer (citado por Pinotti, 2003), que descreveram 3 categorias: bem diferenciado, 
moderadamente diferenciado e pouco diferenciado, estabelecendo seqüência numérica inversa à utilizada para graduação histológica, ou seja, graus 3, 2, 1. Mais tarde, Fisher et al (citado por Pinotti, 2003), propuseram com sucesso que a descrição numérica fosse em seqüência crescente.

Vários estudos têm demonstrado que a ocorrência de células citoqueratinas positivas na medula óssea de pacientes com câncer de mama está associada a prognóstico ruim, constituindo fator que indica recidiva precoce da doença (Bischoff et al, 2003). Por outro lado, a presença de células tumorais circulantes ainda não é utilizada como fator prognóstico (Cristofanili et al, 2004), embora a sua disseminação tenha sido reconhecida como causa de metástase (Pierga et al, 2004) e as mesmas sejam classificadas como malignas (Cristofanili et al, 2004). O potencial de metástase de células tumorais "in vivo" foi relatado por Pretlow et al (2000) (citado por Gaforio et al, 2003). No estudo de Pretlow et al (2000), o sangue periférico obtido de pacientes com carcinoma de próstata ou carcinoma de cólon metastáticos foram injetados em camundongos. Encontraram células de metástases nos pulmões desses animais.

As células neoplásicas do câncer de mama começam a migrar para a circulação sangüínea em estádio precoce (Gaforio et al, 2003), entretanto, sua habilidade para estabelecer metástase e futura recidiva ainda não está bem esclarecida (Racila et al, 1998). Se as células circulam na corrente sangüínea, então seria possível detectá-las no sangue periférico antes que a metástase cresça o suficiente para ser detectada pelos exames convencionais. A detecção precoce das células tumorais circulantes poderia 
representar fator prognóstico e, conseqüentemente teria implicações terapêuticas (Gaforio et al, 2003; Taubert et al, 2004). A análise do sangue periférico contribuir-se-ia em alternativa menos invasiva do que o aspirado de medula óssea, por ser de fácil obtenção, apesar das características biológicas dessas células tumorais circulantes serem ainda desconhecidas (Müller et al, 2005).

Várias pesquisas na década passada tiveram seu foco no desenvolvimento de novos métodos, mais sensíveis e específicos, para a detecção de células neoplásicas circulantes (Martin et al, 1998; Naume et al, 1998; Šafarík \& Šafaríková, 1999), apesar de ocorrerem na freqüência de aproximadamente 1 célula tumoral por $1 \times 10^{5-7}$ de células mononucleares do sangue periférico. Os métodos de identificação dessas células devem distinguir entre as células epiteliais e as hematopoéticas do sangue periférico (Smerage \& Hayes, 2006).

A identificação precoce dessas células é o ponto crucial para o tratamento do câncer de mama, podendo ser considerada uma ferramenta na monitorização da terapia em pacientes com metástase de câncer de mama (Müller et al, 2005).

Análises altamente sensíveis combinando 0 enriquecimento imunomagnético com análise por citometria de fluxo, imunocitoquímica e reação em cadeia da polimerase (PCR) têm sido desenvolvidas para detectar, enumerar e caracterizar as células de carcinoma de mama em sangue periférico (Racila et al, 1998). 
A citometria de fluxo (CMF) tem sido utilizada para detectar células circulantes, permitindo analisar grande quantidade de células em pouco tempo. É capaz de identificar 1 célula epitelial em $1 \mathrm{~mL}$ de sangue periférico (Racila et al, 1998). Sua principal desvantagem é a impossibilidade de se correlacionar com a análise morfológica (Fetsch et al, 2000; Hu et al, 2003), o que pode, por vezes, levar a resultado falso-positivo (Chabannon et al, 2001).

A imunocitoquímica é técnica com alta especificidade e sensibilidade (Gaforio et al, 2003) e considerado o padrão ouro para a detecção das células epiteliais circulantes na corrente sangüínea (Kruger et al, 2000; Lalle et al, 2000). Usualmente, usa-se a fosfatase alcalina antifosfatase alcalina (APAAP), uma técnica simples e de fácil padronização, que permite diferenciar as células de linhagem hematopoética (Chabannon et al, 2001). Entretanto, não permite análise quantitativa e o tempo consumido no teste é elevado.

Alguns estudos empregaram a reação em cadeia da polimerase em tempo real (RT-PCR), técnica dez vezes mais sensível (Kruger et al, 2000), para detectar a presença de células circulantes em câncer de mama e de próstata. Contudo, dependendo da metodologia utilizada ou da seleção dos "primers", pode-se ter resultado falso-positivo. A expressão da citoqueratina 19 e do antígeno carcinoembriônico (CEA) podem ser induzidas nos leucócitos pelas citoquinas e pelo fator de crescimento, proporcionando diminuição da sensibilidade e da especificidade do teste (Racila et al, 1998; Smerage \& Hayes, 2006). 
Martin et al (1998), estudaram 34 pacientes com carcinoma de mama avançado ( $n=22$, média de idade 58 anos), próstata ( $n=6$, média de idade 69 anos), pulmão ( $n=4$, média de idade 75 anos), reto ( $n=1$, idade 63 anos) e cólon ( $\mathrm{n}=1$, idade 55 anos). Foi aplicada a técnica de separação imunomagnética, análise por citometria de fluxo e imunocitoquímica. $\mathrm{Na}$ citometria de fluxo utilizaram o anticorpo anti-citoqueratina 8 (CAM 5.2) para células epiteliais e CD45 (pan leucocitário) para distinguir os leucócitos enquanto na imunocitoquímica foi usado o anticorpo A45B/B3 contra citoqueratinas $8,18,19$. Foram detectadas células epiteliais em 12 de 21 câncer de mama, 4 de 6 câncer de próstata, 3 de 4 câncer de pulmão e no câncer de reto e de cólon. Concluíram que essa técnica descrita pode ser valiosa na quantificação e caracterização molecular de células de carcinoma metastático em tecidos hematopoéticos podendo ser útil no diagnóstico, prognóstico e monitoramento de pacientes com carcinoma.

Cristofanilli et al (2004), em estudo prospectivo, multicêntrico, estudaram o sangue periférico (volume $7,5 \mathrm{~mL}$ ) de 177 pacientes (média de idade de 58 anos) com câncer de mama metastático. O método utilizado foi o sistema de enriquecimento com o kit "CellSearch system" (Immunocom). A identificação e enumeração das células tumorais circulantes foi executada com o "CellLSportter analyzer", que é composto de microscópio fluorescente semi-automatizado, que permite a reconstrução da imagem celular. Obtiveram os seguintes resultados: pacientes com níveis de células tumorais circulantes igual ou maior que 5 por $7,5 \mathrm{~mL}$ de sangue periférico, comparado com o grupo com menor que 5 células tumorais circulantes por $7,5 \mathrm{~mL}$, 
tiveram menor sobrevida livre de progressão $(2,7$ meses $X 7$ meses, $p<0,001)$ e menos sobrevida total $(10,1$ meses $X 18$ meses, $p<0,001)$. Após a primeira visita do início do tratamento essa diferença entre os grupos persistiu (sobrevida livre de progressão, 2,1 meses $X$ 7,0 meses, $p<0,001$, sobrevida total 8,2 meses $X>18$ meses, $p<0,001$, e a redução da proporção das pacientes de $49 \%$ para $30 \%$ ) no grupo com prognóstico desfavorável sugeriram que havia benefício com a terapia. Concluíram que o número de células tumorais antes do tratamento seria um fator preditivo independente da sobrevida livre de progressão e da sobrevida total em pacientes com câncer metastático.

Bauernhofe et al (2005) avaliaram o sangue periférico de 32 pacientes com câncer de mama no estádio IV e de 23 controles normais. Utilizaram o enriquecimento com microbeads HEA 125 e posterior detecção das células por imunocitoquímica, com o anticorpo monoclonal A45B/B3 com revelação por APAAP. Observaram que das 8 das 32 (25\%) pacientes com a neoplasia apresentaram células citoqueratina positivas $(\mathrm{CK}+)$, o que não foi observado em nenhum dos casos controle. Nas pacientes $\mathrm{CK}_{+}, 8$ evoluíram com doença progressiva e 9 de 24 pacientes (37,5\%) citoqueratina negativa (CK-) mostraram doença progressiva. A média de sobrevida das pacientes $\mathrm{CK}+$ foi de $4+/-2$ meses, comparativamente a $13+/-7$ meses das pacientes CK $(p<0,001)$. Concluíram que a detecção de células circulantes periféricas pode estar correlacionada com a progressão da doença e menor sobrevida.

Hu et al (2003) avaliaram o sangue periférico $(20 \mathrm{~mL})$ de 36 pacientes com carcinoma de mama antes da cirurgia. As amostras foram divididas em 
dois grupos: grupo 1, em que foi aplicada a técnica de enriquecimento das células com microbeads seguida de imunocitoquímica (MACS/ICC), e grupo 2 no qual foi utilizado somente imunocitoquímica (ICC). No grupo ICC encontraram apenas 5,6\% (2/36) de pacientes com CK +; enquanto no grupo MACS/ICC foi de 38,9\% (14/36). No grupo MACS/ICC, os casos positivos foram $0 \%$ no estádio I; 33,3\% (8/24) no II; $50 \%$ (3/5) no III e 100\% (3/3) no estádio IV $(p<0,05)$. Portanto, a presença de células circulantes se correlacionou com o estádio clínico.

Kasimir-Bauer et al (2001) pesquisaram células citoqueratinas positivas na medula óssea e marcadores tumorais no sangue periférico de 128 pacientes com câncer de mama primário. Para determinar a eficácia do método de separação imunomagnética, foram comparados dois grupos: o primeiro utilizando somente imunocitoquímica (ICC) e, o segundo, a separação imunomagnética seguida de imunocitoquímica (IMS/ICC) com o anticorpo A45B/B3 e revelação com APAAP. A média total de células CK + foi de $34 \%$ (44/128 pacientes), dos quais $29 \%$ (15/51) para tumores $\mathrm{T} 1,33 \%$ (28/84) para pacientes N0 e 31\% (26/82) para pacientes com câncer de mama G1 e G2. A comparação entre os métodos IMS e ICC foi de 70/128 pacientes $(28 / 70 \mathrm{CK}+)$, sendo que em $6 / 28$ pacientes foram detectados por ambos os métodos, 16/28 somente por ICC e 6/28 somente pela IMS. Após 2 anos, 7/128 pacientes recaíram (3/7CK+/TM-; 2/7 CK-/TM+; 2/7 CK-/TM-). Concluíram que o estudo do aspirado de medula óssea para células $\mathrm{CK}+$ por imunocitoquímica em combinação com a determinação de marcadores tumorais é útil para identificar pacientes com alto risco de recidiva. 
Entretanto, a técnica de enriquecimento deverá ser ainda aperfeiçoada para o uso clínico.

O estudo da quantificação celular, índice de DNA (IDNA) e a fase "S" (proliferação celular), pela citometria de fluxo também podem ser aplicadas. O estudo do DNA é freqüentemente usado para determinar a agressividade do câncer de mama no tratamento primário (Leivonen et al, 1994).

A literatura tem mostrado associação entre a fração da fase "S" e aumento do risco da recidiva e mortalidade para pacientes com linfonodo negativo ou linfonodo positivo em câncer de mama invasivo (Hedley et al, 1993).

Os dados referem que câncer de mama operável com índice de DNA (IDNA) igual a 1,0 (diplóide) tem prognóstico favorável; maior que 2,0 (hiperdiplóides, que compreendem de 4 a $7 \%$ dos casos) tem prognóstico desfavorável; os hipodiplóides, ou seja, com índice de DNA menor que 1,0 são mais raros (apenas $2 \%$ dos casos) também tem associação com prognóstico desfavorável (Hedley, 1993).

Leivonen et al (1994) estudaram retrospectivamente em 132 pacientes a quantificação do DNA de 96 tumores primários e de 53 metástases. Demonstraram que a média do índice de DNA foi de 1,4 e a fase "S" foi de $9,4 \%$, sendo que $36,5 \%$ dos tumores eram diplóides. A diferença de índice de DNA entre os diferentes estádios não foi significante, mas a fase "S" foi significantemente maior no estádio III que no IV. Nos estádios I e II, as pacientes com fase " $\mathrm{S}$ " baixa tiveram maior sobrevida, assim como também ocorreu com as pacientes com índice de DNA igual a 1,0 e fase "S" baixa. 
Visscher et al (1990) assinalaram que a associação entre aneuploidia e fase "S" e o estádio da doença não está ainda clara; os tumores aneuplóides estão associados com fase "S" elevada e menor sobrevida livre de doença, enquanto os diplóides com fase "S" baixa têm maior sobrevida livre de doença; o conteúdo de DNA aneuplóide acha-se significantemente associado com o decréscimo dos marcadores morfológicos e a diferenciação bioquímica.

Assim, em virtude da paucidade de estudos na literatura quanto à identificação de células neoplásicas na corrente sangüínea em pacientes com câncer de mama, propusemo-nos a realizar o presente estudo. 
OBJETIVOS 


\section{OBJETIVOS}

Em mulheres com carcinoma de mama no estádio clínico III, propusemo-nos a detectar a presença de células epiteliais malignas no sangue periférico, por meio dos seguintes métodos:

1) imunocitoquímica;

2) citometria de fluxo;

3) análise quantitativa de DNA no tumor primário da mama. 
MÉTODOS 


\section{MÉTODOS}

\subsection{CASUÍSTICA}

Foram estudadas, prospectivamente, 42 pacientes, sendo 32 portadoras de carcinoma ductal invasivo (CDI) (Grupo A) e 10 pacientes com doença benigna da mama (Grupo B) atendidas no Centro de Referência da Saúde da Mulher - Hospital Peróla Byington - CRSM e no Hospital das Clínicas da Faculdade de Medicina da Universidade de São Paulo (HCFMUSP) no período de outubro de 2004 a abril de 2006.

O projeto foi aprovado pelo Comitê de Ética e pesquisa (CAPPesq) do Hospital das Clínicas e da Faculdade de Medicina da Universidade de São Paulo em sessão de 25/03/04 (Anexo A). Todas as pacientes assinaram o termo de consentimento livre e esclarecido (Anexos B e C). 


\section{Critérios de inclusão}

1) mulheres com idade menor ou igual a 70 anos;

2) boas condições clínicas;

3) diagnóstico histológico de carcinoma de mama ductal invasivo;

4) estádio clínico III;

5) indicação de quimioterapia neoadjuvante.

\section{Critérios de exclusão}

1) ciclo grávido-puerperal;

2) qualquer câncer prévio;

3) carcinoma bilateral sincrônico;

4) radioterapia prévia;

5) hormonioterapia prévia.

As pacientes foram divididas em 2 grupos:

- Grupo A: 32 pacientes com diagnóstico de carcinoma de mama estádio III (Anexo 4D).

- Grupo B: 10 pacientes portadoras de tumor benigno da mama (Anexo E).

Em ambos os grupos, foram colhidas amostras de sangue periférico, grupo $\mathrm{A}$, volume médio $16,95 \mathrm{~mL}$ (Anexo $\mathrm{F}$ ) e grupo $\mathrm{B}$, volume médio 16,5 $\mathrm{mL}$ (Anexo G). Aplicou-se a técnica para a detecção e caracterização das células epiteliais por separação imunomagnética com utilização de microbeads seguida de imunocitoquímica, identificando-a com anticorpo monoclonal anti-citoqueratina.

Nos dois grupos o sangue periférico foi colhido por venoclise no membro superior e contralateral ao tumor primário. 


\subsection{TÉCNICA UTILIZADA}

Procedeu-se a separação de células epiteliais por técnica imunomagnética, por seleção positiva, utilizando-se microbeads. Esses microbeads são compostos de óxido de ferro e polissacarídeo em uma suspensão coloidal estável composta de partícula de 50nm de diâmetro, que não sedimenta ou precipita no campo magnético, são biodegradáveis e a incubação e o processamento são rápidos e não ocorre ativação das células, alteração de função ou viabilidade celular.

Caracterizaram-se as células obtidas pelo estudo citomorfológico e pela técnica imunocitoquímica com a demonstração de citoqueratinas 8,18 e 19 (A45B/B3).

\subsubsection{Material: sangue periférico.}

O sangue periférico (frasco $5,0 \mathrm{~mL}$, anticoagulante etilenodiaminotetracético - EDTA) foi submetido a contagem hematológica no aparelho XE 2100 da Sysmex, obtendo-se os seguintes parâmetros: contagem global dos leucócitos com sua respectiva contagem diferencial, contagem global das hemáceas, dosagem de hemoglobina, hematócrito, volume corpuscular médio e contagem de plaquetas (Anexos $F$ e G). A amostra foi utilizada na sua totalidade. 
Análise do material obtido do sangue periférico, congelado, pela citometria de fluxo, utilizando dupla marcação com anticorpo monoclonal pan leucocitário de superfície (CD45) e citoqueratina (CAM 5.2) intracitoplasmático, com a finalidade de verificar a presença de células epiteliais.

\subsubsection{Material: fragmento de tumor}

O material foi obtido durante a cirurgia, quando se retirou um fragmento de aproximadamente 2,0 X 2,0 cm do tumor. Foi colocado em meio de cultura RPMI 1640 com soro bovino fetal (meio de transporte que tem como finalidade a preservação das células até o momento da realização da análise).

Quantificação de DNA, utilizando-se a técnica de Vindelov (Vindelov \& Christensen, 1990) para obtenção do índice de DNA e fase "S" (proliferação celular) do tumor. 


\subsection{PROCEDIMENTOS TÉCNICOS}

Reagentes, materiais e equipamentos utilizados (Anexos $\mathrm{H}, \mathrm{I}$ e J).

\subsubsection{Fases para obtenção das células epiteliais do sangue periférico}

Foi realizado a partir do enriquecimento e separação imunomagnética com microbeads e caracterização das mesmas por imunocitoquímica com o emprego de anticorpos monoclonais específicos para células epiteliais.

\section{FASE 1}

\section{a) Preparo da amostra}

- Proceder à contagem hematológica (hemograma) da amostra de sangue periférico.

- Confeccionar 2 lâminas de sangue periférico, e secá-las ao ar.

- Centrifugar todo o material, 35 minutos a 300 XG, temperatura entre 18 a $22^{\circ} \mathrm{C}$ (Fig. 1A).

- Desprezar o sobrenadante e transferir a camada leucocitária (camada branca) para um tubo de ensaio de $50 \mathrm{~mL}$.

- Adicionar $30 \mathrm{~mL}$ de solução A (tampão de diluição), reagente de diluição (“diluition buffer" do kit de "carcinoma enrichment cell”, Miltenyi Biotec).

- Adicionar $5 \mathrm{~mL}$ da solução permeabilizante (Cell Perm, kit de "carcinoma enrichment cell"; Miltenyi Biotec). 
- Incubar exatamente por 5 minutos (Fig. 1B).

- Adicionar $5 \mathrm{~mL}$ da solução fixante ("Cell Fix", kit de "carcinoma enrichment cell”; Mltenyi Biotec).

- Incubar por 30 minutos à temperatura ambiente (Fig. 1C).

- Centrifugar por 10 minutos, $300 \mathrm{XG}$, com temperatura entre 18 a $22^{\circ} \mathrm{C}$.

- Desprezar o sobrenadante.

- Lavar uma vez com a solução B, tampão de marcação ("Cell Stain", "kit de carcinoma enrichment cell”; Miltenyi Biotec).

- Ressuspender a amostra em 600uL de solução B (“Cell Stain”).

- Pipetar 200 uL de reagente bloqueador (“FcR blocking reagent”).

- Pipetar 200 uL de "microbeads" revestido com anticorpo monoclonal; citoqueratina ("MACS cytokeratin microbeads") (Fig. 1D).

- Incubar por 45 minutos, com temperatura entre 20 a $25^{\circ} \mathrm{C}$.

- Adicionar $4 \mathrm{~mL}$ de solução B ("Cell Stain").

- Centrifugar por $10 \mathrm{~min}, 300 \mathrm{XG}$, com temperatura entre 20 a $25^{\circ} \mathrm{C}$.

- Desprezar o sobrenadante.

- Ressuspender com 1,0 mL de solução A.

- Proceder à separação imunomagnética.

\section{b) Separação imunomagnética}

- Montar a coluna de separação (tipo LD), colocar o filtro pré coluna sobre a coluna.

- Lavar a coluna com 3X 500 uL de solução A (Fig. 1E).

- Submeter as células na coluna e lavá-las 3X com a solução A. 
- Após o término da passagem da amostra, remover a coluna do campo magnético (Fig. 1F).

- Retirar as células da coluna em um tubo de ensaio lavando a coluna com $1,0 \mathrm{~mL}$ de solução $A$.

- Proceder à contagem celular em câmara de Neubauer.

- Confeccionar citospin, em lâminas revestidas com silane (Anexo K), com aproximadamente 400.000 cels $/ \mathrm{mm}^{3}$.

- Fixar as lâminas com álcool absoluto. Deixá-las no álcool.

- Proceder à reação imunocitoquímica.

Figura 1 - Procedimento técnico utilizado para a detecção de células epiteliais na circulação

Fig. $1 \mathrm{~A}$

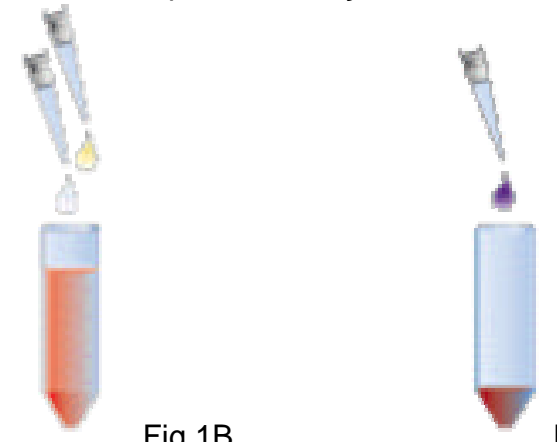

Fig.1B

Fig. $1 \mathrm{C}$

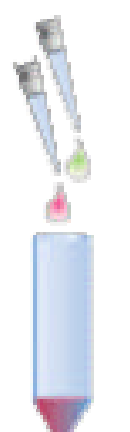

Fig. 1 D

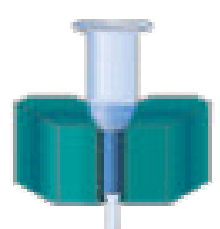

Fig. 1E

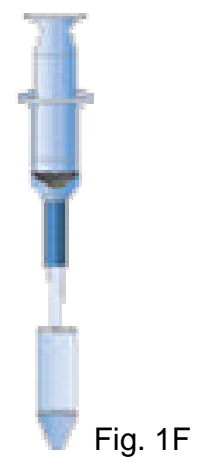




\section{FASE 2}

\section{a) REAÇÃO IMUNOCITOQUÍMICA}

\section{BLOQUEIO DA PEROXIDASE ENDÓGENA}

- Desprezar o álcool e lavar as lâminas em água corrente por 3 minutos.

- Proceder 2 banhos com água destilada.

- Proceder 8 banhos de 5 minutos cada, com água oxigenada 10 volumes.

- $\quad$ (este procedimento de incubação deve ser realizado no escuro).

- Lavá-las por 3 minutos em água corrente.

- Enxaguá-las em água destilada, 2 vezes.

- Deixar escorrer a água.

- Preparar uma caixa de incubação, colocar papel toalha embebida com água, para que o ambiente permaneça úmido durante toda a incubação.

- Dispor as lâminas deitada, pipetar 40 uL do bloqueador da peroxidase.

- Incubar durante 15 minutos em temperatura 18 a $22^{\circ} \mathrm{C}$, no escuro.

\section{b) REAÇÃO PRIMÁRIA}

- Desprezar o bloqueador e pipetar $40 \mathrm{uL}$ do anticorpo monoclonal primário citoqueratina 8-18; 8-19, diluído 1/7 com PBS e EDTA ( $\mathrm{pH}=8$ ).

- Incubar uma noite ("overnight"), na geladeira, temperatura entre 3 a $8^{\circ} \mathrm{C}$, no escuro.

- No dia seguinte, retirar as lâminas da incubadora e lavá-las em 3 banhos de 3 minutos em PBS (sem azida). 


\section{c) REAÇÃO SECUNDÁRIA}

- Retirar o excesso do PBS (sem azida) e incubá-las, 40 minutos, com 40 uL com o anticorpo secundário diluído 1/200 em PBS (sem azida) + albumina $5 \%$ na estufa à $37^{\circ} \mathrm{C}$.

- Retirar as lâminas da incubadora e lavá-las em 3 banhos de 3 minutos com PBS (sem azida).

- Incubar 30 minutos, com 40 uL do anticorpo terciário diluído 1/200 em PBS (sem azida) na estufa a $37^{\circ} \mathrm{C}$.

- Retirar as lâminas da incubadora e lavá-las em 3 banhos de 3 minutos com PBS (sem azida).

\section{d) REVELAÇÃO E COLORAÇÃO}

- Preparar a solução de DAB - diamino benzidina-(100mL de PBS+ albumina 5\% + DAB 50mg - filtrar a solução e posteriormente adicionar 5 $\mathrm{mL}$ de água oxigenada). Essa solução deve ser preparada no momento da reação;

- Retirar o excesso de água das lâminas e incubá-las na solução de DAB por 4 minutos a temperatura entre 18 a $22^{\circ} \mathrm{C}$;

- Retirar as lâminas e lavá-las 3 minutos em água corrente, enxaguá-las em água destilada;

- Proceder à coloração com hematoxilina de Harris (previamente filtrada) por 1 minuto. 


\section{e) DESIDRATAÇÃO}

Proceder aos seguintes banhos de 1 a 2 minutos em cada cuba

Álcool $70 \%$

Álcool 95\%

3 banhos de álcool absoluto 100\%

3 banhos de xilol.

\section{f) MONTAGEM DAS LÂMINAS}

- Proceder à montagem da lâmina com resina de montagem (permount); deixar secar.

- A fase da contracoloração com Hematoxilina de Harris, desidratação e montagem foi realizado utilizando o aparelho Leica ST 5020 e Leica CV5030.

\section{g) LEITURA}

- A leitura foi realizada em microscópio por 2 observadores (1 analista de laboratório e 1 patologista), ocular de 40X e 100X imersão. 


\section{h) INTERPRETAÇÃO DO RESULTADO}

- As células epiteliais apresentam coloração amarela-acastanhada enquanto as demais permanecem azuladas (Fig. 2).

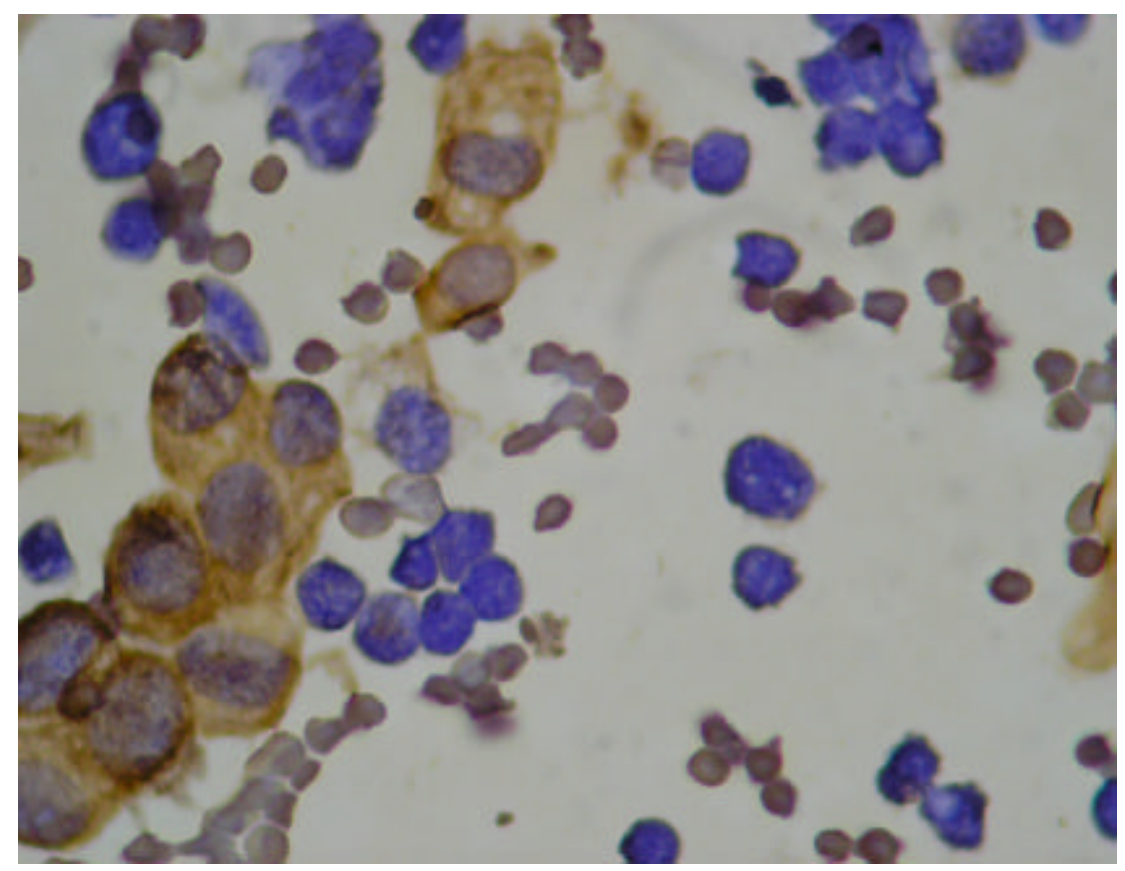

Fig. 2 


\subsubsection{Quantificação do DNA celular no carcinoma invasivo de mama}

- Em uma placa de Petri, colocar 1,5 mL de meio de cultura RPMI 1640 e o fragmento de tumor; dissociar o tumor com o auxílio de uma tesoura com ponta curva, com movimentos delicados. Após total dissociação do tumor, filtrar a solução em filtro de nylon de 22 micra em um tubo de ensaio.

- Centrifugar 5 minutos $1300 \mathrm{rpm}$ a uma temperatura entre 18 a $22 \stackrel{\circ}{\circ}$.

- Ressuspender o sedimento, contar o número de células (fazer uma diluição 1/20 em RPMI e contar em câmara de Neubauer), obter aproximadamente $10^{5}$ cells $/ \mathrm{mm}^{3}$.

- Paralelamente obter sangue controle (paciente supostamente normal), proceder a separação das células mononucleares, para obtenção dos linfócitos.

- Ressuspender o sedimento, contar o número de células (fazer uma diluição 1/20 em RPMI) e contar em câmara de Neubauer. Obter aproximadamente $10^{5}$ cells $/ \mathrm{mm}^{3}$.

- A coloração das células é realizada da seguinte forma:

Identificar 3 tubos de ensaio especial para leitura em citômetro de fluxo com os números 1, 2, 3 e as iniciais do paciente.

No tubo 1 pipetar 200 uL do controle (linfócitos).

No tubo 2 pipetar $100 \mathrm{uL}$ do controle (linfócitos) + 100uL das células da amostra do tumor.

No tubo 3 pipetar 200uL das células da amostra do tumor. 
Em seguida em cada tubo colocar 175 uL da solução A. Incubar 10 minutos; pipetar 162 uL da solução B. Incubar 10 minutos; pipetar 162uL da solução C. Incubar no mínimo 1 hora.

- A incubação deve ser feita em temperatura entre 18 a $22^{\circ} \mathrm{C}$, no escuro.

- Posteriormente proceder a leitura em citômetro de fluxo, utilizando-se o programa DNA QC, no aparelho FACScalibur - Becton Dickinson (BD).

- O resultado é analisado no programa Modfit LT em forma de histograma.

- A análise da ploidia do DNA da população do tumor foi determinada como descrito por Barlogie et al; 1978:

Índice de DNA = média do canal do pico G0/G1 da amostra (tumor) média do canal do pico G0/G1 células controle /linfócitos 
Valores do Índice de DNA (DNA ploidia) (Shankey et al, 1993).

Ploidia

Diplóide (2n) (Fig. 3a)

Aneuplóide (diferente de 2n) (Fig. 3b) IDNA diferente de 1,0

Hiperdiplóide

Hipodiplóide

Tetraplóide (4n) (Fig. 3c)

Multiplóide (Fig. 3d)

Fig. 3 a

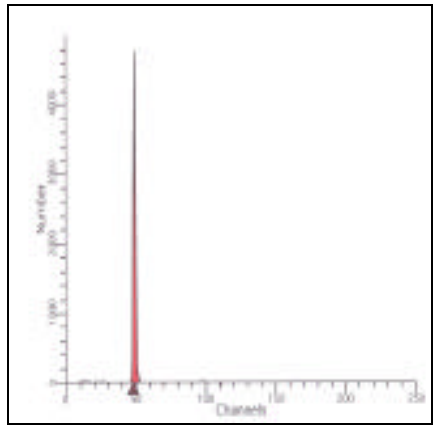

Fig. $3 \mathrm{c}$

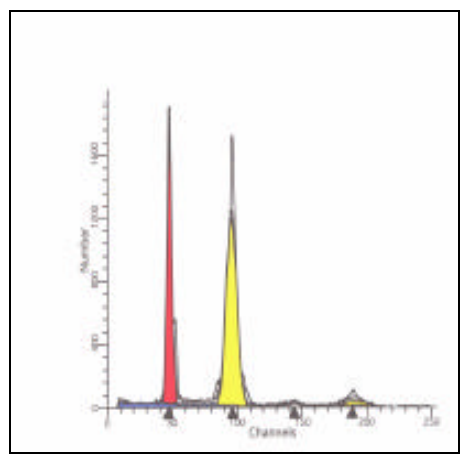

\section{Índice de DNA}

IDNA $=1,0$

$>1,0$

$<1$

IDNA entre os valores 1,9 a 2,1

Presença de mais de 2 picos

Fig. $3 \mathrm{~b}$

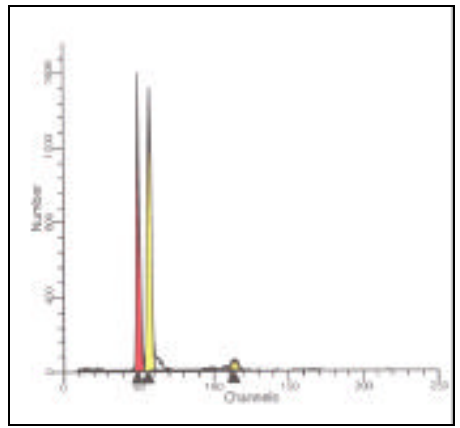

Fig. $3 d$

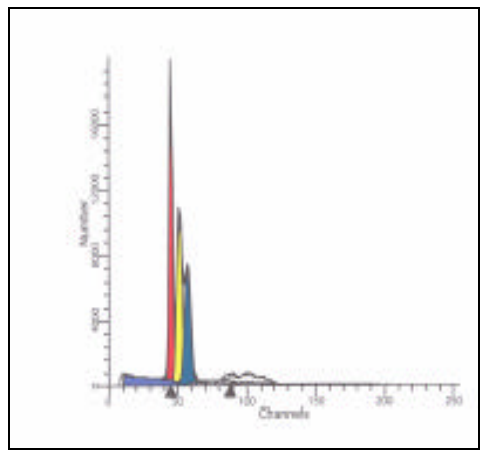


Intervalo da atividade proliferativa (fase "S"):

Baixa menor que $5 \%$

Intermediária de $5 \%$ a $10 \%$

Elevada maior que $10 \%$

Tumores sólidos devem conter no mínimo $20 \%$ de células tumorais para o cálculo da atividade proliferativa (fase "S") (Shankey et al, 1993).

Para avaliar a presença de células epiteliais no tumor em todas as amostras obtidas realizaram-se imunocitoquímica utilizando anticorpo anticitoqueratina para determinar a porcentagem de células neoplásicas. O resultado é considerado positivo para células epiteliais tumorais pela presença de $20 \%$ mais ou menos de células tumorais coradas por campo em aumento de 40X. 


\subsubsection{Análise por citometria de fluxo (Anexo L)}

Utilizando-se o material congelado, que restou do sangue periférico das pacientes dos Grupos A e B, efetuou-se a análise por citometria de fluxo para verificar a presença de citoqueratina nas células epiteliais, como segue: -Descongelar o material conservado a $-70^{\circ} \mathrm{C}$, através de choque térmico, em banho $37^{\circ} \mathrm{C}$ até o seu total descongelamento.

-Lavar 2 vezes, com PBS+ soro bovino fetal (SBF) $2 \%$.

-Ressuspender e marcar com CD45 e CAM 5.2 intracitoplasmático.

-Incubar 20 minutos a uma temperatura entre 4 e $8 \stackrel{\circ}{\circ}$.

-Lavar por 2 vezes com tampão.

-Ressuspender com 1,0 mL de tampão.

-Leitura realizada no citômetro de fluxo FACScalibur -BD.

Antes de proceder à leitura em citômetro de fluxo, o aparelho deve ser lavado com hidróxido de sódio por 20 minutos, posteriormente 1 hora com água destilada, sendo que o filtro da máquina deve ser desligado, e por último o aparelho deverá se estabilizado com PBS por aproximadamente 1 hora.

É considerado positivo quando as células apresentam ligação com citoqueratina, no caso, conjugada com fluoresceína (Fig. 4), enquanto as demais células são negativas para citoqueratina e positivas para CD45 (pan leucocitário).

Foi considerado como positivo presença de pelo menos 10 células citoqueratina positivas. 


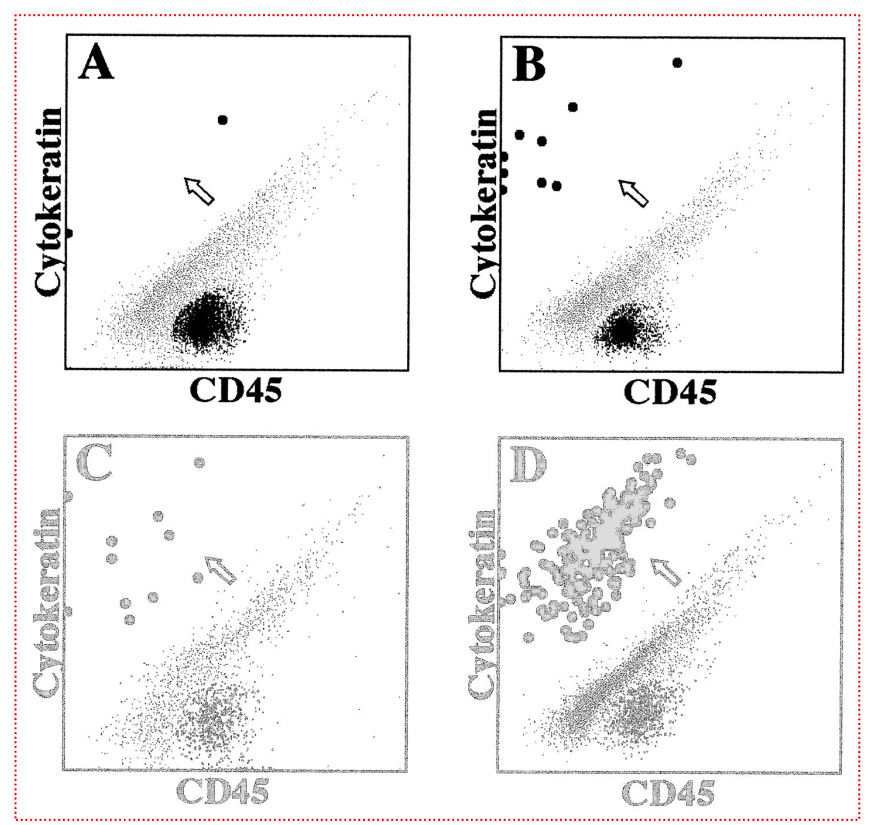

Figura 4: Células citoqueratina positivas.

Racila et al.(1998).

Para avaliar a eficácia da técnica utilizada, isto é, a separação imunomagnética, executou-se um estudo preliminar. Assim, foram analisadas amostras controles obtidas de 12 mulheres sem doença mamária (volume $25 \mathrm{~mL}$ de sangue periférico), às quais foram adicionadas células de cultura epiteliais (células de cultura HELA, células epiteliais provenientes de tumor de útero).

A média de recuperação das células epiteliais adicionadas variou de $66,0 \%$ a $87 \%$; duas amostras tiveram baixa recuperação (54\%). Tais dados demonstraram a eficácia da técnica. 
Quadro 2 - Recuperação

\begin{tabular}{|c|c|c|}
\hline $\begin{array}{c}\text { Caso } \\
\text { nº }\end{array}$ & $\begin{array}{c}\text { №. de células } \\
\text { Hela }\end{array}$ & $\begin{array}{c}\text { Recuperação } \\
(\%)\end{array}$ \\
\hline 1 & 500 & 81,2 \\
\hline 2 & 525 & 54,4 \\
\hline 3 & 105 & 72,0 \\
\hline 4 & 113 & 82,4 \\
\hline 5 & 111 & 87,0 \\
\hline 6 & 124 & 78,0 \\
\hline 7 & 104 & 70,0 \\
\hline 8 & 85 & 70,0 \\
\hline 9 & 70 & 77,0 \\
\hline 10 & 80 & 66,0 \\
\hline 11 & 112 & 85,0 \\
\hline 12 & 100 & 54,0 \\
\hline
\end{tabular}

A técnica selecionada no presente estudo foi o método direto, onde o anticorpo é conjugado aos "microbeads" que são adicionados diretamente na amostra, com separação imunomagnética e posterior análise por imunocitoquímica utilizando a revelação com diaminobenzidina. As amostras também foram avaliadas por meio da citometria de fluxo.

A técnica basicamente consiste na marcação das células epiteliais de câncer de mama do sangue periférico, com anticorpo monoclonal anticitoqueratina $7 / 8$ (CAM 5.2), conjugado a "microbeads" superparamagnéticos. Para que esse processo ocorra, as células são submetidas à permeabilização da membrana celular utilizando detergente, com posterior fixação da mesma com formaldeído.

Para o enriquecimento celular, as células, após a marcação magnética, são submetidas a uma coluna de separação que é acoplada a um magneto permanente (que cria um campo de gradiente magnético elevado). As células que estão marcadas com "microbeads" (células epiteliais) ficarão 
retidas na coluna enquanto as demais células epiteliais passarão através da coluna. Após a remoção da coluna do magneto, as células retidas são eluídas e estão prontas para serem utilizadas. Após a obtenção da amostra enriquecida, duas técnicas de detecção das células epiteliais podem ser aplicadas:

- Imunocitoquímica

- Análise por citometria de fluxo

Neste estudo também foram obtidos fragmentos dos tumores, para análise quantitativa do DNA celular.

A técnica consiste em dissociação mecânica do fragmento, filtragem do material em filtro de nylon de 22 micra, contagem celular do sedimento diluído 1/20 em PBS, utilizando a câmara de Neubauer, coloração do núcleo e leitura em citômetro de fluxo. 
RESULTADOS 


\section{RESULTADOS}

\subsection{IMUNOCITOQUÍMICA NO SANGUE PERIFÉRICO}

A reação de imunocitoquímica no sangue periférico foi negativa em todos os casos.

\subsection{CITOMETRIA DE FLUXO NO SANGUE PERIFÉRICO}

A citometria de fluxo realizada em 23 casos no Grupo A, foi positiva em 22 e negativa em um caso (caso 12-A). Nos 4 casos em que foi realizada no Grupo B foi negativo (Quadros 3 e 4).

\subsection{ANÁLISE QUANTITATIVA DE DNA}

A análise efetuada em 22 pacientes do Grupo A (Quadro 5) revelou:

4.3.a. Em relação ao índice de DNA:

- 9 aneuplóides (casos números: 1-A, 4-A, 5-A, 11-A, 17-A, 18-A, 21-A, 25-A, 26-A);

- 10 diplóides (casos números: 7-A, 9-A, 10-A, 12-A, 13-A, 14-A, 15-A, 16-A, 19-A, 22-A);

- 2 tetraplóides (casos números: 3-A, 6-A);

- 1 multiplóide (caso número 20-A); 
4.3.b) Em relação a atividade proliferativa (fase "S"):

- Baixa (menor que 5\%) em 10 pacientes (casos números: 7-A, 9-A, 10-A, 12-A, 13-A, 14-A, 15-A, 16-A, 19-A, 22-A); todos os casos eram diplóides.

- Intermediária (entre 5\% e 10\%) em 7 pacientes (casos números: 1-A, 4-A, 5-A, 6-A, 18-A, 21-A, 26-A), sendo que 1 caso era diplóide, 1 tetraplóide e 5 aneuplóides.

- Elevada (maior que 10\%) em 5 pacientes (casos números: 3-A, 11-A, 17-A, 20-A, 25-A), sendo 1 caso multiplóide, 1 tetraplóide, 3 aneuplóides. 


\section{Quadro 3- Resultados da citometria de fluxo do Grupo A}

\begin{tabular}{|c|c|c|c|c|c|}
\hline $\begin{array}{l}\text { Caso } \\
\text { número }\end{array}$ & Iniciais & Registro & $\begin{array}{l}\mathrm{N}^{0} \text {. de } \\
\text { eventos }\end{array}$ & $\begin{array}{c}\mathrm{N}^{0} \text {. de células } \\
\mathrm{CK}+\end{array}$ & $\begin{array}{l}\text { Evolução } \\
6 \text { meses }\end{array}$ \\
\hline 1 & SS & 505855 & $\mathrm{Nr}$ & $\mathrm{Nr}$ & Quimioterapia \\
\hline 2 & MSS & 460055 & 6.836 .895 & 24 & Quimioterapia \\
\hline 3 & KK & 522106 & $\mathrm{Nr}$ & $\mathrm{Nr}$ & Radioterapia \\
\hline 4 & DMC & 519675 & $\mathrm{Nr}$ & $\mathrm{Nr}$ & $\begin{array}{l}\text { Múltiplos nódulos no tórax, } \\
\text { múltiplas lesões osteolíticas } \\
\text { em cervical, metástase no } \\
\text { SNC }\end{array}$ \\
\hline 5 & $\mathrm{GI}$ & 516592 & $\mathrm{Nr}$ & $\mathrm{Nr}$ & $\begin{array}{l}\text { Recidiva local em região de } \\
\text { prolongamento axilar }\end{array}$ \\
\hline 6 & MLG & 521394 & $\mathrm{Nr}$ & $\mathrm{Nr}$ & Controle \\
\hline 7 & CABM & 520755 & $\mathrm{Nr}$ & $\mathrm{Nr}$ & Radioterapia e quimioterapia \\
\hline 8 & MAF & 523303 & 8.508 .780 & 30 & $\mathrm{Nr}$ \\
\hline 9 & RPA & 522861 & 2.220 .030 & 44 & Radioterapia \\
\hline 10 & ES & 522346 & 159.060 & 61 & Óbito \\
\hline 11 & LSS & 103277 & 693.675 & 36 & Quimioterapia \\
\hline 12 & MSN & 518173 & 4.905.315 & 5 & $\begin{array}{l}\text { Recidiva em mama E na } \\
\text { região da cicatriz QSE }\end{array}$ \\
\hline 13 & CAAO & 524559 & 2.175 .255 & 37 & Radioterapia \\
\hline 14 & MELSR & 522740 & 4.236 .255 & 45 & Tratamento \\
\hline 15 & MR & 521056 & 3.814 .425 & 45 & Tratamento \\
\hline 16 & VMO & 524656 & 2.634 .750 & 64 & Radioterapia \\
\hline 17 & LAS & 522829 & 3.657 .150 & 30 & Radioterapia \\
\hline 18 & TSA & 267220 & 3.420 .630 & 40 & Quimioterapia \\
\hline 19 & VLP & 524643 & 925.275 & 32 & Radioterapia \\
\hline 20 & ES & 524632 & 1.523 .385 & 22 & Radioterapia \\
\hline 21 & MJIS & 524397 & $\mathrm{Nr}$ & $\mathrm{Nr}$ & Quimioterapia \\
\hline 22 & VMP & 480390 & 1.285 .275 & 52 & Óbito \\
\hline 23 & MBFS & 523827 & 716.850 & 14 & Óbito \\
\hline 24 & $\mathrm{IZH}$ & 161884 & 7.210 .815 & 29 & Quimioterapia \\
\hline 25 & ICS & 523192 & 3.066 .240 & 19 & $\begin{array}{l}\text { Metástase óssea, recidiva } \\
\text { local }\end{array}$ \\
\hline 26 & EMC & 199088 & 1.135 .905 & 47 & Radioterapia \\
\hline 27 & MPB & 527151 & $\mathrm{Nr}$ & $\mathrm{Nr}$ & Óbito \\
\hline 28 & ACAC & 527506 & $\mathrm{Nr}$ & $\mathrm{Nr}$ & Quimioterapia \\
\hline 29 & MJG & 528718 & 681.810 & 29 & Óbito \\
\hline 30 & NSN & 531578 & 15.018 .480 & 138 & Óbito \\
\hline 31 & PS & 529256 & 1.216 .200 & 100 & Óbito \\
\hline 32 & BM & 535233 & 1.124 .625 & 63 & Quimioterapia \\
\hline
\end{tabular}


Quadro 4 - Resultados da citometria de fluxo nas pacientes do Grupo B

\begin{tabular}{|l|l|l|l|l|}
\hline Caso & Iniciais & Registro & $\begin{array}{c}\text { №. de } \\
\text { células ck+ }\end{array}$ & $\begin{array}{c}\text { №. de } \\
\text { eventos }\end{array}$ \\
\hline 1 & MJF & $2269656 \mathrm{I}$ & $\mathrm{Nr}$ & - \\
\hline 2 & AGB & $2816779 \mathrm{~J}$ & 6 & 1.227 .585 \\
\hline 3 & MVA & $3346062 \mathrm{~B}$ & $\mathrm{Nr}$ & - \\
\hline 4 & FCS & $3333990 \mathrm{~B}$ & 2 & 331.980 \\
\hline 5 & ISS & $13613511 \mathrm{~J}$ & $\mathrm{Nr}$ & - \\
\hline 6 & MJC & $2208336 \mathrm{~B}$ & 1 & 656.995 \\
\hline 7 & ECR & $55385442 \mathrm{~A}$ & 2 & 662.595 \\
\hline 8 & MCGS & $3275852 \mathrm{C}$ & $\mathrm{Nr}$ & - \\
\hline 9 & LM & $13489074 \mathrm{~F}$ & $\mathrm{Nr}$ & - \\
\hline 10 & GSS & $13602759 \mathrm{D}$ & $\mathrm{Nr}$ & - \\
\hline
\end{tabular}


Quadro 5 - Resultados da análise quantitativa de DNA do grupo A

\begin{tabular}{|c|c|c|c|c|}
\hline Caso & Iniciais & Registro & IDNA & Fase "S" \\
\hline 1 & SS & 505855 & 1,77 & 5,29 \\
\hline 2 & MSS & 460055 & $\mathrm{Nr}$ & 22,49 \\
\hline 3 & KK & 522106 & 1,9 & 5,94 \\
\hline 4 & $\mathrm{DMC}$ & 519675 & 1,14 & 5,94 \\
\hline 5 & $\mathrm{Gl}$ & 516592 & 1,67 & 9,7 \\
\hline 6 & MLG & 521394 & 2,0 & 7,36 \\
\hline 7 & CABM & 520755 & 1,0 & 1,58 \\
\hline 8 & MAF & 523303 & $\mathrm{Nr}$ & - \\
\hline 9 & RPA & 522861 & 1,0 & 1,44 \\
\hline 10 & ES & 522346 & 1,0 & 1,29 \\
\hline 11 & LSS & 103277 & 1,85 & 19,0 \\
\hline 12 & MSN & 518173 & 1,0 & 1,0 \\
\hline 13 & CAAO & 524559 & 1,0 & 1,09 \\
\hline 14 & MELSR & 522740 & 1,0 & 1,0 \\
\hline 15 & $\mathrm{MR}$ & 521056 & 1,0 & 3,81 \\
\hline 16 & VMO & 524656 & 1,0 & 1,35 \\
\hline 17 & LAS & 522829 & 2,81 & 13,92 \\
\hline 18 & TSA & 267220 & 1,54 & 6,31 \\
\hline 19 & VLP & 524643 & 1,0 & 2,51 \\
\hline 20 & ES & 524632 & 1,$14 ; 1,27$ & 3,$58 ; 19,38$ \\
\hline 21 & MJIS & 524397 & 1,44 & 9,79 \\
\hline 22 & VMP & 480390 & 1,0 & 0,83 \\
\hline 23 & MBFS & 523827 & $\mathrm{Nr}$ & - \\
\hline 24 & $\mathrm{IZH}$ & 161884 & $\mathrm{Nr}$ & - \\
\hline 25 & ICS & 523192 & 1,69 & 18,78 \\
\hline 26 & EMC & 199088 & 1,69 & 5,2 \\
\hline 27 & MPB & 527151 & $\mathrm{Nr}$ & - \\
\hline 28 & ACAC & 527506 & Óbito & - \\
\hline 29 & MJG & 528718 & Óbito & - \\
\hline 30 & NSN & 531578 & Óbito & - \\
\hline 31 & PS & 529256 & Óbito & - \\
\hline 32 & BM & 535233 & Óbito & - \\
\hline
\end{tabular}


DISCUSSÃO 


\section{DISCUSSÃO}

A detecção precoce das células do câncer de mama é o ponto crucial para o sucesso do tratamento. Entretanto, muitos tumores permanecem clinicamente ocultos até tornarem-se avançados; por esse motivo estudamos uma técnica que auxilie na detecção precoce das células tumorais em tecidos de fácil obtenção, como é o sangue periférico.

As técnicas existentes tendem a ser aperfeiçoadas e analisadas para a obtenção de resultados mais rápidos, específicos e confiáveis.

Neste projeto propusemos-nos a testar um método que está sendo empregado para se identificar células raras em determinados tecidos como, o sangue periférico e a medula óssea, por meio da separação de células com o emprego de "microbeads", identificando as células epiteliais por imunocitoquímica com revelação por peroxidase. $\mathrm{O}$ uso da revelação por peroxidase foi adotada por ser técnica que possui uma coloração mais intensa e por ser mais específica do que a técnica com APAAP.

O resultado da pesquisa de células epiteliais no sangue periférico com a técnica de separação de células utilizando "microbeads" acoplados a citoqueratina com revelação por imunocitoquímica com peroxidase foi negativa neste estudo, ao passo que a de células epiteliais por citometria de fluxo foi positiva.

Analisando os resultados pela imunocitoquímica concluímos que o número de células obtidas após o enriquecimento celular foi muito grande, devido à contaminação por células hematopoéticas que se fixaram na coluna 
de separação e, assim ficaram retidas mesmo após a lavagem da coluna com o tampão. Essa grande quantidade de células dificultou a leitura das lâminas, pois, se fossem confeccionadas com todo o material obtido teríamos elevado número de lâminas, inviável para se fazer a reação por ser alto custo e elevado tempo consumido para a sua realização. Decidiu-se, então, confeccionar 8 lâminas, com um total de $2,5 \times 10^{6}$ células por lâmina.

$\mathrm{Na}$ literatura, as células epiteliais do sangue periférico foram reveladas utilizando a técnica com APAAP, relativamente simples, onde as células obtidas do enriquecimento já são imediatamente marcadas com o anticorpo monoclonal específico. Em seguida, confeccionaram-se as lâminas, que foram reveladas com APAAP e a leitura realizada em microscópio óptico (Kasimir-Bauer et al, 2001; Bischoff et al, 2003; Braun et al, 2000; Racila et al, 1998).

Em nosso estudo, optamos por utilizar a revelação por peroxidase, técnica mais elaborada, onde, primeiramente, confeccionam-se as lâminas com as células obtidas do enriquecimento. Posteriormente, são submetidas ao bloqueio da peroxidase endógena as células, principalmente os neutrófilos que possuem altos níveis de peroxidase endógena, com a utilização de água oxigenada 10 volumes em vários banhos (total de 8 banhos de 5 minutos cada). Em seguida, faz-se então a marcação com o anticorpo monoclonal, com o anticorpo secundário, o complexo peróxido e revelação com diaminobenzidina. Talvez os banhos em água oxigenada possam ter alterado a estrutura celular, dificultando, a obtenção de resultado positivo. 
Pela citometria de fluxo, observamos que o resultado foi positivo praticamente na sua totalidade. Tal achado denota ser a técnica sensível, porém pouco específica. Não há, pois, condições de se estudar a morfologia celular para a identificação das células epiteliais, o que pode gerar falso positivo.

A grande vantagem deste método é que se pode utilizar o número total de células obtidas, mesmo em grandes quantidades, pois, permite que se faça a leitura de todo o material, sem alto custo, como na imunocitoquímica.

Outro grande problema é a escolha do anticorpo monoclonal para a identificação das células. Neste trabalho, tentamos utilizar o anticorpo mais citado na literatura, porém, não da mesma procedência, ou seja, o CK3E4 (Bauernhofer et al, 2005; Martin et al, 1998; Küger et al, 2000), que identifica células com citoqueratinas 8,18 e 19. Contudo, se tivéssemos usado um anticorpo pan citoqueratina, que engloba número maior de tipos de citoqueratina, talvez obtivéssemos melhor resultado, uma vez que restringimos ao máximo o tipo de citoqueratina.

Em algumas lâminas observamos a presença de células danificadas, em decorrência da centrifugação das mesmas.

Outra dificuldade encontrada na imunocitoquímica é com a morfologia das células, pois, com a técnica de enriquecimento, estas sofrem processo inicial de permeabilização, com o tampão que contém em sua formulação um detergente que possibilita a abertura dos poros permitindo a entrada dos "microbeads". Posteriormente as células são fixadas com tampão contendo formaldeído, o que faz com que os poros permaneçam abertos. Todo esse 
processo pode alterar a morfologia celular dificultando a sua identificação. Ao inverso, na citometria estas modificações não são observadas, pois, identificam-se células que apresentam o anticorpo epitelial conjugado com fluorescência apenas.

$\mathrm{Na}$ citometria de fluxo foi utilizado o anticorpo monoclonal CAM 5.2 (pan citoqueratina), onde estão presentes vários tipos de citoqueratinas.

Em três estudos independentes que avaliaram vários anticorpos monoclonais para a detecção de células tumorais disseminadas, demonstrou-se que este produz marcação uniforme (90\%) em amostras de carcinoma primário de vários órgãos, incluindo mama, próstata e pulmão, fixadas com formalina (Makin et al, 1984; Poston e Sidhu,1986; Thomas e Battifora $\mathrm{H}, 1987)$. Mostraram ainda que os anticorpos contra citoqueratinas intracelulares são superiores aos que reconhecem o tecido específico ou a superfície de células epiteliais.

Não foi aplicada a técnica de separação de células por ficol hypaque em virtude do risco de perda celular, entretanto, muitos estudos aplicaram esta técnica antes do enriquecimento com microbeads, eliminando grande parte das células hematopoéticas (Pierga et al,2004; Taubert et al, 1992; Naume et al, 1998).

Em síntese, o enriquecimento celular com revelação por peroxidase, apesar de boa técnica, para ser executada na rotina é por deveras trabalhosa, onerosa e pouco prática. 
Talvez possa ser realizada por APAAP, desde que o número de células obtidas pelo enriquecimento permita que se faça um número menor de lâminas para a reação.

Já a citometria de fluxo parece ser mais adequada para a rotina devido a sua praticidade, mas, não é específica. 
CONCLUSÕES 


\section{CONCLUSÕES}

Nas mulheres com carcinoma de mama no estádio clínico III, concluímos que:

1- Não foi possível detectar a presença de células epiteliais malignas no sangue periférico através da imunocitoquímica.

2- A citometria de fluxo permitiu a identificação das células epiteliais, mas não foi possível o estudo citomorfológico das células.

3- O estudo do índice de DNA no tumor primário não foi homogêneo.

4- A detecção e caracterização de células tumorais circulantes em pacientes com câncer de mama pode vir a se constituir em um novo fator prognóstico, porém, são ainda necessárias novas estratégias para melhor detectá-las. 
ANEXOS 


\section{Anexo A}

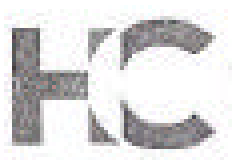

\section{DIDETOPIA GLNIGA}

Comissä́o de Ético pora Análite de Projetos de Pesguisa

\section{APROVACAOO}

A Comissío de Ético paro Andise de Projetar de Prespien - CAPPesq da biretoria Clinica do Hospitel das Girvas e do Foculdude de Medicina do Universidade de Sä Paulo, em sessió de 25.03.04, APROVOU o Protomolo de Pesquisa n" 173/04. intitulada: "Deteccibo e caracterizaçōo de ellulas epiteliais no sangue periferico en pacientes con carciroma de memo nas estódios III e IV apresentado pelo beportamento de onstetricia E GINecoloolA, inclushe o Term de Conoentimento Lhe $e$ Esthrecida:

Fesquisodor (a) Responsunel: Prof. Dr. Jose Aristodemo Pinottl Pesquisodor(a) Executarite Sra. Yomi Hasegawa Maekawa.

CAPPesq, 25 de Morge de 2004.

$$
\text { Wh } \quad 40 \mathrm{~h}
$$

MOF, DR EUCLIDES AYRES DE CASTILHO Prosidsnte de Censisazo de Étion para Ansilise de Projetor de Proquiro

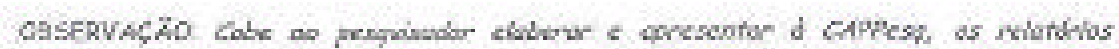

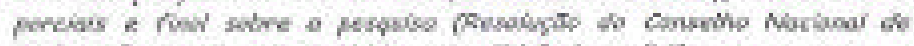

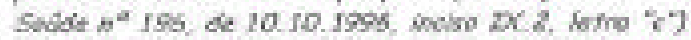




\section{Anexo B}

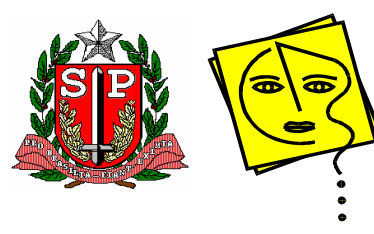

\section{SECRETARIA DE ESTADO DA SAÚDE}

Centro de Referência da Saúde da Mulher

\section{Comitê de Ética em Pesquisa}

\section{III- REGISTRO DAS EXPLICAÇÕES DO PESQUISADOR AO PACIENTE OU SEU REPRESENTANTE LEGAL SOBRE A PESQUISA, CONSIGNANDO:}

1.justificativa e os objetivos da pesquisa - Para o acompanhamento da sua doença a senhora terá que colher o seu sangue, o objetivo deste estudo é avaliar se o seu sangue ainda tem a sua doença.

2.procedimentos que serão utilizados e propósitos, incluindo a identificação dos procedimentos que são experimentais - Conforme foi comentado, a senhora será submetida a coleta de sangue durante o seu tratamento.

3.desconfortos e riscos esperados -Como a senhora sabe, durante o seu tratamento toda vez que a senhora vier para consulta fazer o exame de sangue no laboratório (hemograma), vamos colher o seu sangue para analisar se ainda tem a sua doença no sangue. Na coleta de sangue vamos amarrar um garrote (tipo de elástico) no seu braço para acharmos a sua veia, vamos colocar uma agulha na veia e vamos retirar o sangue, a senhora vai sentir uma picada, pode ser que ocorra o aparecimento de hematomas (que são manchas roxas na pele).

4.benefícios que poderão ser obtidos -Com esta pesquisa, da qual a senhora está participando, tentamos descobrir se com os exames de sangue, poderíamos diagnosticar o reaparecimento da sua doença, se acontecer da doença voltar.

5. procedimentos alternativos que possam ser vantajosos para o indivíduo. Não tem, por enquanto, o melhor tratamento para o câncer de mama é a cirurgia juntamente com a quimioterapia para acompanhamento da doença

Vide Informações ao paciente e consentimento informado no anexo VII. 
IV -ESCLARECIMENTOS DADOS PELO PESQUISADOR SOBRE GARANTIAS DO SUJEITO DA PESQUISA:

1. acesso, a qualquer tempo, às informações sobre procedimentos, riscos e benefícios relacionados à pesquisa, inclusive para dirimir eventuais dúvidas.

2. liberdade de retirar seu consentimento a qualquer momento e de deixar de participar do estudo, sem que isto traga prejuízo à continuidade da assistência.

3. salvaguarda da confidencialidade, sigilo e privacidade.

4. disponibilidade de assistência no CRSMNADI, por eventuais danos à saúde, decorrentes da pesquisa.

5. viabilidade de indenização por eventuais danos à saúde decorrentes da pesquisa.

V. INFORMAÇÕES DE NOMES,ENDEREÇOS E TELEFONES DOS RESPONSÁVEIS PELO ACOMPANHAMENTO DA PESQUISA, PARA CONTATO EM CASO DE INTERCORRÊNCIAS CLÍNICAS E REAÇÕES ADVERSAS.

\section{OBSERVAÇÕES COMPLEMENTARES:}

\section{VII - CONSENTIMENTO}

Declaro que, após convenientemente esclarecido pelo pesquisador e ter entendido o que me foi explicado, consinto em participar da presente Pesquisa

São Paulo, de de.

assinatura do sujeito da pesquisa ou responsável legal 
MODELO DA CARTA DE CONSENTIMENTO DO CHEFE DE SERVIÇO ONDE SERÁ REALIZADA A PESQUISA

São Paulo de. de.

\section{Ao \\ Comitê de Ética em Pesquisa do CRSM}

Prezados Senhores,

INFORMO PARA OS DEVIDOS FINS, QUE CONHEÇO E CONCORDO COM A REALIZAÇÃO DA PESQUISA..”DETECÇÃO E CARACTERIZAÇÃO DE CÉLULAS EPITELIAIS NO SANGUE PERIFÉRICO EM PACIENTES COM CÂNCER DE MAMA EM ESTADIOS III , DA PESQUISADOR(A) YUMI Hasegawa MaEkawa SOB orientaçÃo de .Prof. Dr. José ARISTOdEMO PINOTTI, DA FACULDADE DE MEdICINA DE SÃO PAULOFMUSP, DENTRO DO SETOR DE ONCOLOGIA.

Dr.(a).Antônio Carlos T. Nisida

Diretor. 


\section{Anexo C

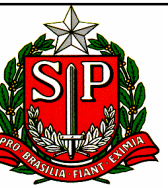 \\ HOSPITAL DAS CLÍNICAS \\ da Faculdade de Medicina da Universidade de SÃo PaUlo \\ Caixa Postal, 8091 - São Paulo - Brasil \\ Anexo I \\ TERMO DE CONSENTIMENTO LIVRE E ESCLARECIDO}

(Instruções para preenchimento no verso)

\section{I - DADOS DE IDENTIFICAÇÃO DO SUJEITO DA PESQUISA OU RESPONSÁVEL LEGAL}

1. NOME DO PACIENTE .

DOCUMENTO DE IDENTIDADE № : SEXO : .M ? F ?

DATA NASCIMENTO:

ENDEREÇO

$. / \ldots \ldots . . . . . . .$.

... №

BAIRRO

CEP:.

TELEFONE:DDD

CIDADE.

APTO:

2.RESPONSÁVEL LEGAL

NATUREZA (grau de parentesco, tutor, curador etc.)

DOCUMENTO DE IDENTIDADE :

SEXO: M ? F ?

DATA NASCIMENTO.: .....................

ENDEREÇO:

BAIRRO:

CEP:.

№

APTO: TELEFONE:DDD CIDADE:

\section{II - DADOS SOBRE A PESQUISA CIENTÍFICA}

1. TÍTULO DO PROTOCOLO DE PESQUISA: Detecção e caracterização de células epiteliais no sangue periférico em pacientes com carcinoma de mama nos estádios III.

2. PESQUISADOR: José Aristodemo Pinotti CARGO/FUNÇÃO: Médico INSCRIÇÃO CONSELHO REGIONAL №. UNIDADE DO HCFMUSP: .Disciplina de Ginecologia HCFMUSP

3. AVALIAÇÃO DO RISCO DA PESQUISA:

$\begin{array}{lllll}\text { SEM RISCO } & \text { RISCO MÍNIMO } & x & \text { RISCO MÉDIO } \\ \text { RISCO BAIXO } & \text { RISCO MAIOR } & ? & \end{array}$

(probabilidade de que o indivíduo sofra algum dano como conseqüência imediata ou tardia do estudo)

4.DURAÇÃO DA PESQUISA : aproximadamente 24 meses. 


\section{III - REGISTRO DAS EXPLICAÇÕES DO PESQUISADOR AO PACIENTE OU SEU REPRESENTANTE LEGAL SOBRE A PESQUISA CONSIGNANDO:}

1. justificativa e os objetivos da pesquisa - para o acompanhamento da sua doença a senhora terá que colher o seu sangue, o objetivo deste estudo é avaliar se o seu sangue ainda tem a sua doença .

2. procedimentos que serão utilizados e propósitos, incluindo a identificação dos procedimentos que são experimentais - conforme comentado, a senhora será submetida a coleta de sangue durante o seu tratamento.

3. desconfortos e riscos esperados - Como a senhora sabe, durante o seu tratamento toda vez que a senhora vier para consulta, vamos ter que colher o seu sangue para analisar se ainda tem a sua doença no sangue .Na coleta de sangue vamos amarrar um garrote (tipo de elástico ) no seu braço para acharmos a sua veia, vamos colocar uma agulha na veia e vamos retirar o sangue, a senhora vai sentir uma picada, pode ser que ocorra o aparecimento de hematomas (que são manchas roxas na pele).

4. benefícios que poderão ser obtidos - Com esta pesquisa, da qual a senhora está participando, tentamos descobrir se com os exames de sangue, poderíamos diagnosticar o reaparecimento da sua doença, se acontecer da doença voltar.

5. procedimentos alternativos que possam ser vantajosos para o indivíduo. Não tem, por enquanto, o melhor tratamento para o câncer de mama é a cirurgia juntamente com a quimioterapia para acompanhamento da doença. 


\section{IV - ESCLARECIMENTOS DADOS PELO PESQUISADOR SOBRE GARANTIAS DO SUJEITO DA PESQUISA CONSIGNANDO:}

1. acesso, a qualquer tempo, às informações sobre procedimentos, riscos e benefícios relacionados à pesquisa, inclusive para dirimir eventuais dúvidas.

2. liberdade de retirar seu consentimento a qualquer momento e deixar de participar do estudo, sem que isto traga prejuízo à continuidade da assistência médica.

3. salvaguarda da confidencialidade, sigilo e privacidade.

4. disponibilidade de assistência no HCFMUSP, por eventuais danos à saúde, decorrentes da pesquisa, estando a disposição o Pronto Socorro de Ginecologia e os pesquisadores, nos telefones 3069-6647 e 3082-7394.

5. viabilidade de indenização por eventuais danos à saúde decorrentes da pesquisa.

\section{INFORMAÇÕES DE NOMES, ENDEREÇOS E TELEFONES DOS RESPONSÁVEIS PELO ACOMPANHAMENTO DA PESQUISA, PARA CONTATO EM CASO DE INTERCORRÊNCIAS CLÍNICAS E REAÇÕES ADVERSAS.}

José Aristodemo Pinotti

T: 3069-6000 ramal 6218 Ambulatório de Ginecologia 5ํandar PAMB ou 3082-7394

\section{OBSERVAÇÕES COMPLEMENTARES:}

\section{VII - CONSENTIMENTO PÓS-ESCLARECIDO}

Declaro que, após convenientemente esclarecido pelo pesquisador e ter entendido o que me foi explicado, consinto em participar do presente Protocolo de Pesquisa 


\section{Anexo D}

Dados relevantes das pacientes do Grupo A -

portadoras de carcinoma ductal invasivo de mama estádio clínico III.

\begin{tabular}{|c|c|c|c|c|c|}
\hline $\begin{array}{l}\text { Caso } \\
\text { número }\end{array}$ & Iniciais & Registro & $\begin{array}{l}\text { Idade } \\
\text { (anos) }\end{array}$ & $\begin{array}{l}\text { Estádio } \\
\text { Clínico } \\
\text { (TNM) }\end{array}$ & $\begin{array}{c}\text { Diagnóstico } \\
\text { Ca ductal invasivo (CDI) }\end{array}$ \\
\hline 1 & SS & 505855 & 39 & T2N2 & $\begin{array}{c}\text { grau histológico (SBR) 2, } \\
\text { grau nuclear } 1\end{array}$ \\
\hline 2 & MSS & 460055 & 47 & T3N1 & grau nuclear 2 \\
\hline 3 & $\mathrm{KK}$ & 522106 & 63 & T4dN2Mx & $\begin{array}{c}\text { grau histológico (SBR) } 3, \\
\text { grau nuclear } 3\end{array}$ \\
\hline 4 & DMC & 519675 & 58 & T3N2M0 & $\begin{array}{c}\text { grau histológico (SBR) 2, } \\
\text { grau nuclear } 2\end{array}$ \\
\hline 5 & $\mathrm{GI}$ & 516592 & 46 & T3N1 & $\begin{array}{l}\text { grau nuclear } 2 \text { extensão } \\
\text { lobular presente. }\end{array}$ \\
\hline 6 & MLG & 521394 & 58 & T4bN1Mx & $\begin{array}{c}\text { grau histológico (SBR) 1, } \\
\text { grau nuclear } 2\end{array}$ \\
\hline 7 & CABM & 520755 & 29 & T3N2M0 & grau histológico (SBR) 2 \\
\hline 8 & MAF & 523303 & 53 & T4N2M0 & $\mathrm{Nr}$ \\
\hline 9 & RPA & 522861 & 44 & T3N1Mx & $\begin{array}{c}\text { grau histológico (SBR) 2, } \\
\text { grau nuclear } 2\end{array}$ \\
\hline 10 & ES & 522346 & 47 & T3N1 & $\begin{array}{l}\text { Ca ductal invasivo- } \\
\text { trocater }\end{array}$ \\
\hline 11 & LSS & 103277 & 65 & T3N2M0 & $\begin{array}{c}\text { grau histológico (SBR) } 3, \\
\text { grau nuclear } 2\end{array}$ \\
\hline 12 & MSN & 518173 & 37 & T3N1 & $\begin{array}{c}\text { grau histológico (SBR) 3, } \\
\text { grau nuclear } 3\end{array}$ \\
\hline 13 & CAAO & 524559 & 28 & T3N1M0 & $\begin{array}{c}\text { grau histológico (SBR) 3, } \\
\text { grau nuclear } 3\end{array}$ \\
\hline 14 & MELSR & 522740 & 50 & T3N1M0 & $\begin{array}{c}\text { grau histológico (SBR) 3, } \\
\text { grau nuclear } 2\end{array}$ \\
\hline 15 & $\mathrm{MR}$ & 521056 & 37 & T3N1Mx & grau histológico (SBR) 2 \\
\hline 16 & VMO & 524656 & 43 & T4BN2M0 & $\begin{array}{c}\text { grau histológico (SBR) 2, } \\
\text { grau nuclear } 2\end{array}$ \\
\hline 17 & LAS & 522829 & 48 & T4N1M0 & $\begin{array}{c}\text { grau histológico (SBR) } 3, \\
\text { grau nuclear } 3\end{array}$ \\
\hline 18 & TSA & 267220 & 54 & T2N2M0 & $\begin{array}{c}\text { grau histológico (SBR) 2, } \\
\text { grau nuclear } 2\end{array}$ \\
\hline 19 & VLP & 524643 & 45 & T4N1M0 & $\begin{array}{c}\text { grau histológico (SBR) 2, } \\
\text { grau nuclear } 2\end{array}$ \\
\hline 20 & ES & 524632 & 43 & T4N2M0 & $\begin{array}{c}\text { grau histológico (SBR) 2, } \\
\text { grau nuclear } 2\end{array}$ \\
\hline
\end{tabular}




\begin{tabular}{|c|c|c|c|c|c|}
\hline 21 & MJIS & 524397 & 55 & T3N1 & $\begin{array}{c}\text { grau histológico (SBR) 2, } \\
\text { grau nuclear } 3\end{array}$ \\
\hline 22 & VMP & 480390 & 50 & T3N1 & $\begin{array}{c}\text { com extensão para lóbulo e } \\
\text { extensão intra ductal } \\
\text { grau histológico (SBR) 2, } \\
\text { grau nuclear } 3\end{array}$ \\
\hline 23 & MBFS & 523827 & 46 & T3N2Mx & $\begin{array}{c}\text { grau histológico (SBR) 2, } \\
\text { grau nuclear } 2\end{array}$ \\
\hline 24 & $\mathrm{IZH}$ & 161884 & 65 & T2N2 & $\begin{array}{c}\text { grau histológico (SBR } \\
\text { modificado) 3, grau nuclear } \\
3\end{array}$ \\
\hline 25 & ICS & 523192 & 58 & T2N2Mx & $\begin{array}{c}\text { grau histológico (SBR } \\
\text { modificado) } 3 \text { grau nuclear } \\
2 .\end{array}$ \\
\hline 26 & EMC & 199088 & 58 & T4bN2 & $\begin{array}{c}\text { grau histológico (SBR) 2, } \\
\text { grau nuclear } 2\end{array}$ \\
\hline 27 & MPB & 527151 & 57 & T4dN3Mx & $\begin{array}{l}\text { grau nuclear 2, com } \\
\text { necrose (trocater) }\end{array}$ \\
\hline 28 & ACAC & 527506 & 64 & T4bN2Mx & $\begin{array}{c}\text { infiltração da derme por } \\
\text { carcinoma ductal grau } 2 \\
\text { nuclear }\end{array}$ \\
\hline 29 & MJG & 528718 & 55 & T4dN2Mx & $\begin{array}{l}\text { com embolização linfática } \\
\text {,grau nuclear } 2 \text { (trocater) }\end{array}$ \\
\hline 30 & NSN & 531578 & 58 & T4bN2Mx & $\mathrm{Nr}$ \\
\hline 31 & PS & 529256 & 69 & T4dN2Mx & grau nuclear 2 (trocater) \\
\hline 32 & BM & 535233 & 47 & T4dN2Mx & $\begin{array}{l}\text { Ca ductal" in situ" padrão } \\
\text { sólido grau nuclear } 3 \text { com } \\
\text { microinvasão- inflamatório }\end{array}$ \\
\hline
\end{tabular}




\section{Anexo E}

Dados relevantes das pacientes do Grupo B

\begin{tabular}{|l|l|l|l|l|}
\hline $\begin{array}{l}\text { Caso } \\
\text { número }\end{array}$ & Iniciais & Registro & Idade & Diagnóstico \\
\hline 1 & MJF & $2269656 \mathrm{I}$ & 69 & Ectasia ductal \\
\hline 2 & AGB & $2816779 \mathrm{~J}$ & 53 & Tumor filódes \\
\hline 3 & FCS & $3333990 \mathrm{~B}$ & 18 & Fibroadenoma \\
\hline 4 & ISS & $13613511 \mathrm{~J}$ & 45 & Fibroadenoma \\
\hline 5 & MJC & $2208336 \mathrm{~B}$ & 51 & Fibroadenoma \\
\hline 6 & ECR & $55385442 \mathrm{~A}$ & 60 & Fibroadenoma \\
\hline 7 & MCGS & $3275852 \mathrm{C}$ & 36 & Fibroadenoma \\
\hline 8 & LM & $13489074 \mathrm{~F}$ & 42 & Fibroadenoma \\
\hline 9 & GSS & $13602759 \mathrm{D}$ & 60 & Fibroadenoma \\
\hline 10 & MVA & $3346062 \mathrm{~B}$ & 41 & Fibroadenoma \\
\hline
\end{tabular}




\section{Anexo F}

Hemograma das pacientes do Grupo A

\begin{tabular}{|c|c|c|c|c|c|c|c|}
\hline $\begin{array}{l}\text { Caso } \\
\text { número }\end{array}$ & $\begin{array}{c}\text { WBC } \\
\left.\text { (cels } / \mathrm{mm}^{3}\right)\end{array}$ & $\begin{array}{c}\text { Neutro } \\
\text { (cels/mm³) }\end{array}$ & $\begin{array}{c}\text { Linfo } \\
\left.\text { (cels/mm } / \mathrm{mm}^{3}\right)\end{array}$ & $\begin{array}{c}\mathrm{Hb} \\
(\mathrm{g} / \mathrm{dL})\end{array}$ & $\begin{array}{l}\text { VCM } \\
\text { (fL) }\end{array}$ & plaq $/ \mathrm{mm}^{3}$ & \begin{tabular}{|c} 
Volume \\
sangue \\
periférico \\
$(\mathrm{mL})$
\end{tabular} \\
\hline 1 & 4060 & 1570 & 2100 & 11,8 & 89,0 & 356000 & 15,9 \\
\hline 2 & 9980 & 6630 & 2460 & 12,3 & 77,4 & 416000 & 16,1 \\
\hline 3 & 3450 & 1790 & 1220 & 11,0 & 97,6 & 295000 & 13,4 \\
\hline 4 & 6610 & 4410 & 1820 & 13,0 & 95,6 & 264000 & 14,8 \\
\hline 5 & 9270 & 6210 & 2170 & 10,9 & 84,4 & 401000 & 16,8 \\
\hline 6 & 5930 & 2720 & 2220 & 14,6 & 91,0 & 237000 & 18,1 \\
\hline 7 & 6970 & 4010 & 2200 & 12,4 & 83,9 & 254000 & 18,2 \\
\hline 8 & 9370 & 5220 & 3180 & 13,4 & 92,1 & 296000 & 16,6 \\
\hline 9 & 12880 & 9060 & 3010 & 14,5 & 91,9 & 326000 & 16,9 \\
\hline 10 & 6230 & 3650 & 1850 & 11,4 & 93,3 & 222000 & 20,0 \\
\hline 11 & 4820 & 1520 & 2580 & 14,8 & 93,7 & 284000 & 13,9 \\
\hline 12 & 6260 & 3310 & 2120 & 15,8 & 93,1 & 211000 & 19,1 \\
\hline 13 & 6120 & 4150 & 1430 & 12,4 & 86,4 & 213000 & 17,2 \\
\hline 14 & 8030 & 5550 & 1740 & 10,1 & 73,3 & 352000 & 21,2 \\
\hline 15 & 7200 & 3980 & 2430 & 12,0 & 90,4 & 190000 & 16,8 \\
\hline 16 & 9360 & 7610 & 1330 & 15,7 & 89,4 & 256000 & 16,9 \\
\hline 17 & 9430 & 6440 & 2370 & 13,5 & 91,9 & 252000 & 18,0 \\
\hline 18 & 11530 & 7110 & 3440 & 14,3 & 92,9 & 134000 & 18,3 \\
\hline 19 & 7400 & 4970 & 1800 & 12,6 & 91,2 & 177000 & 17,8 \\
\hline 20 & 9250 & 4460 & 3060 & 12,2 & 86,8 & 230000 & 18,6 \\
\hline 21 & 6170 & 2540 & 2990 & 12,8 & 85,0 & 147000 & 17,6 \\
\hline 22 & 5730 & 3250 & 1980 & 13,5 & 87,4 & 316000 & 18,4 \\
\hline 23 & 8950 & 6460 & 2000 & 12,9 & 86,1 & 290000 & 16,6 \\
\hline 24 & 6440 & 3850 & 1950 & 15,0 & 92,7 & 258000 & 19,1 \\
\hline 25 & 6490 & 4450 & 1400 & 13,8 & 94,2 & 288000 & 16,7 \\
\hline 26 & 6250 & 3140 & 2560 & 14,0 & 86,8 & 242000 & 15,5 \\
\hline 27 & 7280 & 5330 & 1450 & 15,2 & 91,3 & 228000 & 16,5 \\
\hline 28 & 6800 & 3500 & 1500 & 13,0 & 90,0 & 150000 & 16,0 \\
\hline 29 & 6440 & 4200 & 1330 & 11,2 & 75,5 & 299000 & 15,5 \\
\hline 30 & 10540 & 7050 & 1880 & 14,3 & 93,1 & 148000 & 15,5 \\
\hline 31 & 6890 & 3820 & 1790 & 14,4 & 92,7 & 228000 & 14,1 \\
\hline 32 & 9370 & 5560 & 3090 & 14,7 & 81,9 & 369000 & 15,6 \\
\hline média & & & & & & & 16,95 \\
\hline
\end{tabular}




\section{Anexo G}

Hemograma das pacientes do Grupo B

\begin{tabular}{|l|l|l|l|l|l|l|l|}
\hline $\begin{array}{c}\text { Caso } \\
\text { número }\end{array}$ & $\begin{array}{c}\text { WBC } \\
\left(\text { céls } / \mathrm{mm}^{3}\right)\end{array}$ & $\begin{array}{c}\text { Neutro } \\
\left(\text { cels } / \mathrm{mm}^{3}\right)\end{array}$ & $\begin{array}{c}\text { Linfo } \\
\left(\mathrm{cels} / \mathrm{mm}^{3}\right)\end{array}$ & $\begin{array}{c}\mathrm{Hb} \\
(\mathrm{g} / \mathrm{dL})\end{array}$ & $\begin{array}{c}\mathrm{VCM} \\
(\mathrm{fL})\end{array}$ & $\begin{array}{c}\text { Volume } \\
\text { plaq/mm }\end{array}$ & $\begin{array}{c}\text { sangue } \\
\text { periférico } \\
(\mathrm{mL})\end{array}$ \\
\hline 1 & 11830 & 9380 & 1510 & 11,4 & 87,2 & 414000 & 17,4 \\
\hline 2 & 5670 & 3060 & 1980 & 14,5 & 85,5 & 256000 & 14,2 \\
\hline 3 & 6310 & 3650 & 1800 & 13,3 & 89,6 & 232000 & 18,0 \\
\hline 4 & 5190 & 3120 & 1430 & 12,6 & 94,6 & 187000 & 17,5 \\
\hline 5 & 7360 & 4630 & 2050 & 14,5 & 90,5 & 167000 & 15,2 \\
\hline 6 & 7230 & 4530 & 1760 & 14,1 & 91,2 & 386000 & 15,4 \\
\hline 7 & 8000 & 4490 & 2490 & 14,4 & 89,8 & 244000 & 15,4 \\
\hline 8 & 6560 & 3780 & 2130 & 12,7 & 90,3 & 293000 & 17,6 \\
\hline 9 & 6310 & 3890 & 1870 & 13,5 & 87,3 & 206000 & 17,9 \\
\hline 10 & 6610 & 3240 & 2330 & 12,9 & 86,8 & 252000 & 16,4 \\
\hline média & & & & & & & 16,5 \\
\hline
\end{tabular}




\section{Anexo H}

\section{Reagentes}

- Kit: "Carcinoma Cell Enrichment" (código: 130-060-101) Miltenyi biotec.

Este kit contém:

- solução A: tampão concentrado (deve ser previamente diluído 1/10 com água deionizada filtrada em filtro de 0,22 micra),

- solução B: solução de marcação( deve ser previamente diluído 1/10 em solução A), contém detergente.

- solução permeabilizante ("Cell Perm”), contém detergente.

- solução fixante (“Cell Stain”), contém formaldeído.

- solução colóide contendo microbeads conjugado com anticorpo monoclonal citoqueratina 8-18 e 8-19,

- solução bloqueadora ("FcR blocking").

- RPMI 1640 ("Roswell Park Memorial Institute") meio cultura para o transporte do fragmento do tumor.

- SBF (soro bovino fetal), Cultilab.

- anticorpo monoclonal anti citoqueratina (8/19, 8/19), miltenyi biotec (código: 130-090-865).

- Água oxigenada $10 \mathrm{~V}$. 
- PBS + albumina 5\% (albumina bovina a 5\% a $1,25 \mathrm{~mL}$ e PBS $59 \mathrm{~mL}$ ) armazenar a $4^{\circ} \mathrm{C}$.

- Kit de calibração para DNA ("DNA QC particles").

- Anticorpo monoclonal anti - citoqueratina código 347653 BD (clone CAM 5.2) conjugado com fluoresceína (FITC);

- Anticorpo monoclonal, pan leucocitário- CD45 código 555483 BD conjugado com ficoeritrina (PE).

- PBS sem azida

- Salina para citômetro de fluxo ("facsflow"- BD).

- DAB 50mg em 100 mL de PBS ("diaminobenzidine tetrahydrochloride"D5637 sigma código 286)

- Álcool absoluto

- Álcool 92\%

- Álcool 70\%

- Xilol comercial

- Hematoxilina de Harris

- Água destilada

- EDTA pH=8,0 
Reagentes para coloração do DNA nuclear.

Solução de estoque

Tampão citrato de sódio 3,4 mmol/L + Tris 0,5mmol/L + Igepal CA-630,01

(Sigma L3021) (V/V) + Spermine 4HCL 1,5 mmol/L pH=7,6.

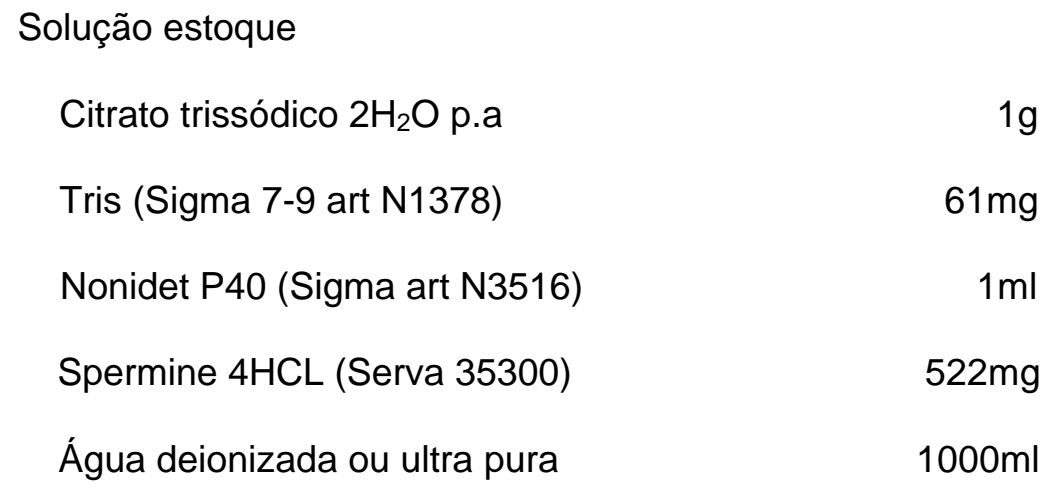

Verificar $\mathrm{pH}$.

Armazenamento 2 a $8^{\circ} \mathrm{C}$.

Validade 1 mês.

Solução A: Tripsina em tampão citrato $\mathrm{pH}=7,6$

$\begin{array}{lr}\text { Tripsina (Sigma T 0134) } & 3 \mathrm{mg} \\ \text { Tampão citrato (solução estoque) } & 100 \mathrm{ml} \\ \text { Verificar pH. } & \end{array}$

Armazenamento 2 a $8^{\circ} \mathrm{C}$.

Validade 1 ano. 
Solução B

Ribonuclease + tripsina inibidora em tampão citrato $\mathrm{pH}=7,6$

Trypsin inhibitor (Sigma T 9253) 50mg

Ribonuclease A (Sigma R5125) 10mg

Tampão citrato (solução estoque) 100ml

Verificar pH (utilizar $\mathrm{NaOH} 0,1 \mathrm{~N}$ )

Armazenamento 2 a $8^{\circ} \mathrm{C}$.

Validade 1 ano.

Solução C

lodeto de prodídio + espermine $4 \mathrm{HCL}$ em tampão citrato $\mathrm{pH}=7,6$

$\begin{array}{lr}\text { lodeto de propídio (Sigma P4170) } & 41,6 \mathrm{mg} \\ \text { Spermine 4HCL (Serva 35300) } & 116,0 \mathrm{mg} \\ \text { Tampão citrato (solução estoque) } & 100,0 \mathrm{ml}\end{array}$

Verificar pH (utilizar $\mathrm{NaOH} 0,1 \mathrm{~N}$ )

Armazenamento 2 a $8^{\circ} \mathrm{C}$.

Validade 1 ano. 


\section{Anexo I}

\section{Materiais}

- Coluna de separação tipo LS (código: 130-042-901) Miltenyi biotec.

- Filtro pré coluna(código: 414-07) Miltenyi biotec.

- Conjunto de separação MidiMACS (suporte e unidade de separação) (código: 130-043-001) Miltenyi biotec.

- Tubo de poliestireno $12 \times 75 \mathrm{~mm}$.

- Pipeta Pasteur descartável.

- Pipetas automáticas e suas respectivas ponteiras.

- Lâmina fosca, revestida com poli-lisina ou silane.

- Tubos cônicos $50 \mathrm{~mL}$

- Placa de Petri descartável

- Tesoura com ponta curva

- Bisturi

- Câmara de Neubauer

- Seringa e agulha fina.

- Beckers

- Tubos de ensaio descartáveis.

- Funil de plástico

- Provetas

- Suporte para lâminas com alça (berço)

- Cubas de vidro com ranhuras

- Lâminas de vidro(extremidade fosca)

- Filtro para citospin cytopad- Wescor cytopro cat SS111.

- Pipeta sorológica $5 \mathrm{~mL}$ 


\section{Anexo J}

\section{Equipamentos}

- Citocentrífuga Wescor-7120 " hematology general staining/cytocentrifugation"

- Centrifuga IEC- CENTRA 8R refrigerada

- Corador de lâminas - Leica ST 5020

- Montador de lâminas - Leica CV 5030

- Contador hematológico - XE2100 Sysmex

- Citômetro de fluxo Fascalibur-BD

- Estufa 37으

- Microscópio óptico em aumento de 40 X e 100X. 


\section{Anexo K}

PREPARO DAS LÂMINAS DE SILANE

Limpar as lâminas e colocá-las nos seguintes banhos:

$1^{\text {a }}$ cuba: acetona pura

$2^{\mathrm{a}}$ cuba: $25 \mathrm{~mL}$ de silane $+475 \mathrm{~mL}$ de acetona pura: deixar 2 minutos

3ㄹ cuba: acetona, deixar 10 segundos

4를 cuba: acetona, deixar 10 segundos

5a cuba: água destilada, deixar 10 segundos

6ª cuba: água destilada, deixar 10 segundos

Após, deixar as lâminas secando, em estufa. 


\section{Anexo L}

\section{Citometria de Fluxo (CMF)}

A citometria de fluxo é um método rápido e objetivo que permite a determinação de múltiplas propriedades físicas simultaneamente de partículas isoladas em suspensão, em nosso caso, as células.

Podemos detectar e quantificar antígenos celulares de superfície, citoplasmáticos e nucleares.

Podem ser analisadas vários tipos de amostras: sangue periférico, aspirado de medula óssea, aspirado de linfonodo, outros fluidos do corpo (líquor, líquido pleural, líquido ascítico) e tecidos sólidos.

Os anticorpos monoclonais utilizados são habitualmente submetidos aos critérios do "International Workshop and Conference on Human Leukocyte Differentiation Antigens", ocasião em que um grupo de laboratórios de referência avalia, caracteriza e classifica os anticorpos submetidos. O primeiro destes "Workshops" ocorreu em Paris em 1982 e o sétimo, na Inglaterra, em 2000. Uma vez aceitos por este colegiado, esses anticorpos recebem a designação CD (“cluster of differentiation”).

Cada CD pode ser representado por vários anticorpos monoclonais que reconhecem o mesmo antígeno, mas não necessariamente o mesmo epítopo, produzidos por diferentes clones de células. Isto explica os comportamentos diferentes entre resultados obtidos com 0 uso de monoclonais diversos. 
A citometria de fluxo mede as propriedades de células em suspensão, orientadas num fluxo laminar e interceptadas uma a uma por um feixe de LASER. As modificações ocasionadas nesse feixe de luz devidas à presença da célula serão então detectadas e mensuradas por sensores(detectores). A luz dispersa é coletada por um sistema óptico que permite identificar as células pelo seu tamanho e granularidade interna. Hemácias, plaquetas, linfócitos, monócitos e granulócitos podem ser assim identificados e quantificados (Fig. 5).

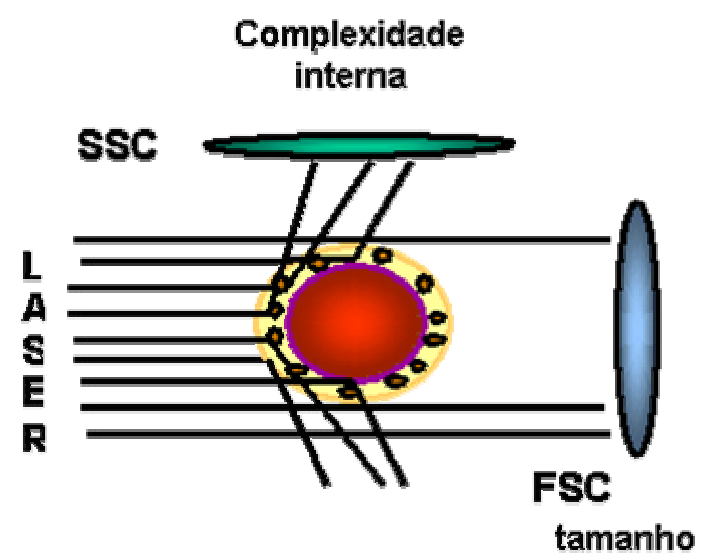

Figura 5- Citômetro de Fluxo: análise das características físicas das células - tamanho e complexidade interna.

Os diferentes fluorocromos que marcam cada antígeno absorvem a luz e emitem-na num comprimento de onda maior e específico. Cada fluorocromo possui um padrão espectral distinto de absorção e emissão, de tal maneira que até quatro cores de luz podem ser opticamente separadas com os filtros seletivos encontrados nos citômetros comuns. Os antígenos 
são então detectados por diferentes detectores de fluorescência permitindo o estudo simultâneo de 3 a 4 antígenos (ex. Anti-CD3 apc, anti-CD45-PerCP, Anti-CD19-isotiocianato de fluoresceína e anti-CD10-ficoeritrina), utilizandose anticorpos monoclonais específicos marcados com diferentes substâncias fluorescentes, em geral através da técnica de imunofluorescência direta (Fig. 6)

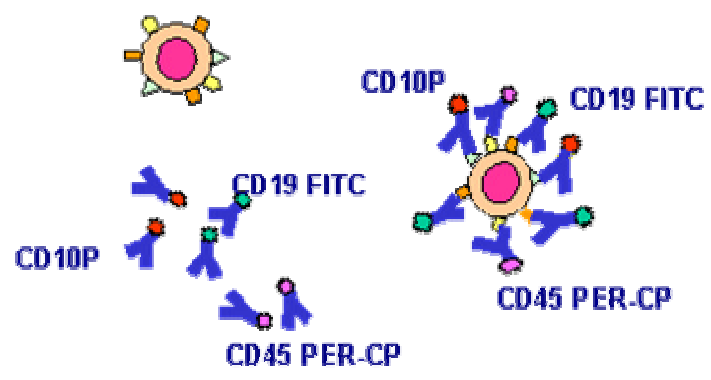

Figura 6- Imunofluorescência Direta.

Os fótons de luz gerados atingem detectores específicos e são convertidos em impulsos elétricos proporcionais ao número de fótons recebidos. Estes impulsos são convertidos em sinais digitais podendo oferecer os resultados em diferentes formas de análise tais como histogramas, "dot-plot", tabelas entre outros (Fig. 7). 


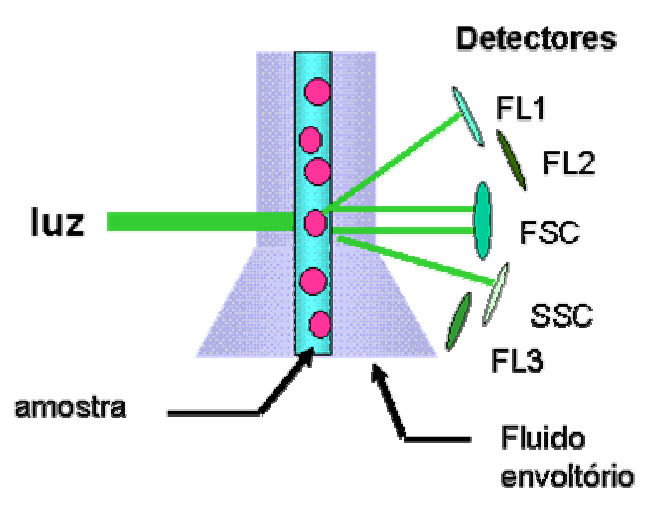

\section{Foto multiplicadores}
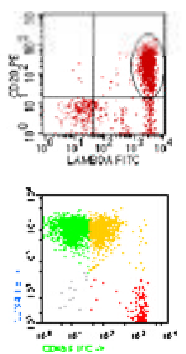

Digita lização

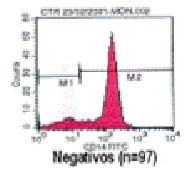

Figura 7- Representação esquemática do citômetro de fluxo.

A citometria de fluxo é técnica rápida, precisa, quantitativa e reprodutível.

A análise da população de células anômalas é realizada através de uma "janela" que pode ser definida de duas maneiras:

1- Baseada no tamanho e complexidade interna das células, equivalente a morfologia celular.

2- Aplicando-se uma "janela" imunológica, isto é, definem-se populações de células especificamente coradas por anticorpos (por exemplo, CD45 de diferentes intensidades e com determinada complexidade interna); uma vez identificada a população de células ela é então caracterizada quanto à linhagem celular. 
REFERÊNCIAS BIBLIOGRÁFICAS 


\section{REFERÊNCIAS BIBLIOGRÁFICAS}

Barlogie B, Gohde W, Johnston DA, Smallwood L, Schumann J, Drewinko B, Freireich EJ. Determination of ploidy and proliferative characteristics of human solid tumors by pulse cytophotometry. Cancer Res. 1978 Oct;38(10):3333-9.

Bauernhofer T, Zenahlik S, Hofmann G, Balic M, Resel M, Pirchmoser R, Regitnig P, Ambros P, Dandachi N, Samonigg H. Association of disease progression and poor overall survival with detection of circulating tumor cells in peripheral blood of patients with metastatic breast cancer. Oncol Rep. 2005 Feb;13(2):179-84.

Bilimoria MM, Morrow M. The woman at increased risk for breast cancer: evaluation and management strategies. CA Cancer J Clin. 1995 SepOct;45(5):263-78

Bischoff J; Rosenberg R; Dahm M; Janni W, Gutschw K. Minimal residual disease en bone marrow and peripheral blood of patients with metastatic breast cancer. Recent results in cancer research, vol 162, 2003, 135-140.

Black MM, Speer FD. Nuclear structure in cancer tissues. Surg Gynecol Obstet. 1957 Jul;105(1):97-102. 
Bloom, H J G \& Richardson W W. Histological grading and prognosis in breast cancer- A study of 1409 cases of which 359 have been followed for 15 years. Br J Cancer, 1957, n. 11, p. 359-77.

Braun S, Pantel K, Muller P, Janni W, Hepp F, Kentenich CR, Gastroph S, Wischnik A, Dimpfl T, Kindermann G, Riethmuller G, Schlimok G. Cytokeratin-positive cells in the bone marrow and survival of patients with stage I, II, or III breast cancer. N Engl J Med. 2000 Feb 24;342(8):525-33.

Chabannon C; Olivero S; Viret F; Arnoule C; Sainty D; Maraninchi D; Viens P. Detection of epithelial cells in hematopoietic organs of patients with breast cancer. Acta Haematol 2001; 105:166-171.

Cristofanilli M, et al. Circulation tumor cells, disease progression and survival in metastatic breast cancer. N Engl J Med, 2004;351: 781-791.

Fetsch PA, MT, Kenneth H Cowan, MD, Ph.D. , David E Weng, MD, Ph.D., Allison Freifield, MD, Armando C Filie, MD, Andrea Abati, MD. Detection of circulating tumor cells and micrometastases in Stage II, III, and IV breast cancer patients utilizing cytology and immunocytochemistry. Diagnostic cytopathology, 2000, 22 (5); 323-328. 
Fisher B, Mamounas EP. Preoperative chemotherapy: a model for studying the biology and therapy of primary breast cancer. J Clin Oncol 1995;13:53740.

Fisher ER, Gregorio RM, Fisher B, Redmond C, Vellios F, Sommers SC. The pathology of invasive breast cancer. A syllabus derived from findings of the National Surgical Adjuvant Breast Project (protocol no. 4). Cancer. 1975 Jul;36(1):1-85.

Gaforio JJ, Serrano MJ, Sanchez-Rovira P, Sirvent A, Delgado-Rodriguez M, Campos M, de la Torre N, Algarra I, Duenas R, Lozano A. Detection of breast cancer cells in the peripheral blood is positively correlated with estrogen-receptor status and predicts for poor prognosis. Int J Cancer. 2003 Dec 20;107(6):984-90.

Hedley DW, Clark GM, Cornelisse CJ, Killander D, Kute T, Merkel D. DNA Cytometry Consensus Conference. Consensus review of the clinical utility of DNA cytometry in carcinoma of the breast. Breast Cancer Res Treat. 1993 Oct;28(1):55-9. Review.

Hortobagyi GN. Multidisciplinary management of advanced primary and metastatic breast cancer. Cancer. 1994 Jul 1;74(1 Suppl):416-23. 
Hu XC, Wang Y, Shi DR, Loo TY, Chow LW. Immunomagnetic tumor cell enrichment is promising in detecting circulating breast cancer cells. Oncology. 2003;64(2):160-5.

Janni W, Gastroph S, Hepp F, Kentenich C, Rjosk D, Schindlbeck C, Dimpfl T, Sommer H, Braun S. Prognostic significance of an increased number of micrometastatic tumor cells in the bone marrow of patients with first recurrence of breast carcinoma. Cancer. 2000 May 15;88(10):2252-9.

Johnson-Thompson MC, Guthrie J. Ongoing research to identify environmental risk factors in breast carcinoma. Cancer. 2000 Mar 1;88(5 Suppl):1224-9.

Kasimir-Bauer S, Oberhoff C, Sliwinska K, Neumann R, Schindler AE, Seeber S. Evaluation of different methods for the detection of minimal residual disease in blood and bone marrow of patients with primary breast cancer: importance for clinical use? Breast Cancer Res Treat. 2001 Sep;69(2):123-32.

Kasimir-Bauer S, Oberhoff C, Schindler AE, Seeber S. A summary of two clinical studies on tumor cell dissemination in primary and metastatic breast cancer: methods, prognostic significance and implication for alternative treatment protocols (Review). Int J Oncol. 2002 May;20(5):1027-34. 
Krüger W, Datta C, Badbaran A, Togel F, Gutensohn K, Carrero I, Kroger N, Janicke F, Zander AR. Immunomagnetic tumor cell selection-implications for the detection of disseminated cancer cells. Transfusion. 2000 Dec;40(12):1489-93.

Lalle M, De Rosa L, Marzetti L, Montuoro A. Detection of breast cancer cells in the bone marrow or peripheral blood: methods and prognostic significance. Tumori. 2000 May-Jun;86(3):183-90.

Leivonen M, Krogerus L, Nordling S. DNA analysis in advanced breast cancer. Cancer Detect Prev. 1994;18(2):87-96.

Lippman ME, Allegra JC, Thompson EB, Simon R, Barlock A, Green L, Huff KK, Do HM, Aitken SC, Warren R. The relation between estrogen receptors and response rate to cytotoxic chemotherapy in metastatic breast cancer. $\mathrm{N}$ Engl J Med. 1978 Jun 1;298(22):1223-8.

Martin VM, Siewert C, Scharl A, Harms T, Heinze R, Ohl S, Radbruch A, Miltenyi S, Schmitz J. Immunomagnetic enrichment of disseminated epithelial tumor cells from peripheral blood by MACS. Exp. Hematol.; 1998 Mar;26(3):252-64. 
Muller V, Stahmann N, Riethdorf S, Rau T, Zabel T, Goetz A, Janicke F, Pantel K. Circulating tumor cells in breast cancer: correlation to bone marrow micrometastases, heterogeneous response to systemic therapy and low proliferative activity. Clin Cancer Res. 2005 May 15;11(10):3678-85.

Naume B, Borgen E, Nesland JM, Beiske K, Gilen E, Renolen A, Ravnas G, Qvist H, Karesen R, Kvalheim G. Increased sensitivity for detection of micrometastases in bone-marrow/peripheral-blood stem-cell products from breast-cancer patients by negative immunomagnetic separation. Int $\mathrm{J}$ Cancer. 1998 Nov 23;78(5):556-60.

Pierga JY, Bonneton C, Vincent-Salomon A, de Cremoux P, Nos C, Blin N, Pouillart P, Thiery JP, Magdelenat $\mathrm{H}$. Clinical significance of immunocytochemical detection of tumor cells using digital microscopy in peripheral blood and bone marrow of breast cancer patients. Clin Cancer Res. 2004 Feb 15;10(4):1392-400.

Pinotti JA .Cancer de mama inicial. São Paulo: BYK ; 2003,capítulo 4; pág. 80-1.

Pinotti JA .Cancer de mama inicial. São Paulo : BYK; 2003, capítulo 3, pág. 61. 
Pretlow TG, Schwartz S, Giaconia JM, Wright AL, Grimm HA, Edgehouse NL, Murphy JR, Markowitz SD, Jamison JM, Summers JL, Hamlin CR, MacLennan GT, Resnick MI, Pretlow TP, Connell CF. Prostate cancer and other xenografts from cells in peripheral blood of patients. Cancer Res. 2000 Aug 1;60(15):4033-6.

Racila E, Euhus D, Weiss AJ, Rao C, McConnell J, Terstappen LW, Uhr JW. Detection and characterization of carcinoma cells in the blood. Proc Natl Acad Sci U S A. 1998 Apr 14;95(8):4589-94.

Šafarík I, Šafaríková M. Use of magnetic techniques for the isolation of cells. Journal of Chromatography B Vol. 722, 33-53.

Shankey TV, Rabinovitch PS, Bagwell B, Bauer KD, Duque RE, Hedley DW, Mayall $\mathrm{BH}$, Wheeless L, ox C. Guidelines for implementation of clinical DNA cytometry. International Society for Analytical Cytology. Cytometry. $1993 ; 14(5): 472-7$.

Smerage JB, Hayes DF. The measurement and therapeutic implications of circulating tumour cells in breast cancer. Br J Cancer. 2006 Jan 16;94(1):812. 
Taubert H, Blumke K, Bilkenroth U, Meye A, Kutz A, Bartel F, Lautenschlager C, Ulbrich EJ, Nass N, Holzhausen HJ, Koelbl H, Lebrecht A. Detection of disseminated tumor cells in peripheral blood of patients with breast cancer: correlation to nodal status and occurrence of metastases. Gynecol Oncol. 2004 Jan;92(1):256-61.

UICC (2002). Classificação TNM de tumores malignos. Sexta ed. John Wiley \& Sons: New York.

Vindelov LL, Christensen IJ. A review of techniques and results obtained in one laboratory by an integrated system of methods designed for routine clinical flow cytometric DNA analysis. Cytometry. 1990;11(7):753-70.

Visscher DW, Zarbo RJ, Greenawald KA, Crissman JD. Prognostic significance of morphological parameters and flow cytometric DNA analysis in carcinoma of the breast. Pathol Annu. 1990;25 Pt 1:171-210.

Weigelt B, Peterse JL, van 't Veer LJ. Breast cancer metastasis: markers and models. Nat Rev Cancer. 2005 Aug;5(8):591-602. Review. 